\title{
PERFIL DE UN JUEZ DEL SEGUNDO NIVEL DE LA CARRERA JUDICIAL BASADO EN HABILIDADES GERENCIALES
}

\section{PROFILE OF A JUDGE OF THE SECOND LEVEL OF THE JUDICIAL CAREER BASED ON MANAGERIAL SKILLS}

\author{
Eva Luz Tamariz Béjar \\ Magíster en Gestión Pública \\ Universidad Cesar Vallejo \\ evatamariz@gmail.com \\ Perú, Lima
}

\section{SUMARIO}

- Introducción

- Antecedentes de estudio

- Planteamientos teóricos

- Método V.-Resultados

- Discusión de resultados

- Conclusiones.

\section{ÍNDICE DE TABLAS}

- Tabla $N^{\circ} 1$ - Distribución de la población censal de jueces del segundo nivel del distrito judicial donde se realizó el estudio, 2018

- Tabla $\mathrm{N}^{\circ} 2$ - Distribución de los tipos de faltas en las que incurrieron los jueces del segundo nivel del distrito judicial donde se realizó el estudio.

- Tabla $N^{\circ} 3$ - Distribución del estado de trámite de procesos disciplinarios de los jueces del segundo nivel del distrito judicial donde se realizó el estudio.

- Tabla $N^{\circ} 4$ - Distribución del tipo de sanciones de los jueces del segundo nivel del distrito judicial donde se realizó el estudio.

- Tabla $N^{\circ} 5$ - Distribución de la necesidad de desarrollo de habilidades gerenciales que coadyuvan las quejas y/o faltas disciplinarias
- Tabla $\mathrm{N}^{\circ} 6$ - Tipo de habilidades gerenciales que necesitan desarrollar los jueces del segundo nivel del distrito judicial donde se realizó el estudio, según sexo y condición laboral.

- Tabla $\mathrm{N}^{\circ} 7$ - Tipo de habilidades gerenciales que necesitan desarrollar los jueces del segundo nivel del distrito judicial donde se realizó el estudio, según su especialidad

\section{ÍNDICE DE FIGURAS}

- Figura $\mathrm{N}^{\circ} 1$ - Distribución porcentual de quejas interpuestas contra los jueces del segundo nivel en el distrito judicial donde se realizó el estudio, 2018.

- Figura $\mathrm{N}^{\circ} 2$ - Niveles porcentuales de desarrollo de habilidades gerenciales de los jueces del segundo nivel del distrito judicial donde se realizó el estudio, 2018.

- Figura $\mathrm{N}^{\circ} 3$ - Incidencia porcentual de la necesidad de desarrollo, por tipo de habilidades gerenciales, de los jueces del segundo nivel del distrito judicial donde se realizó el estudio, 2018.

\section{RESUMEN}

El estudio parte de la incidencia de faltas disciplinarias de los jueces y de la necesidad de desarrollo de habilidades gerenciales. El objetivo general fue diseñar el perfil de un juez del segundo nivel de la carrera, basado en habilidades gerenciales, para disminuir faltas disciplinarias. 
En el marco de la investigación holística, constituye un estudio proyectivo. El diseño de investigación es descriptivo-explicativo, transaccional, de campo y propositivo. La población de estudio estuvo constituida por la población censal, conformada por 43 jueces del segundo nivel de un distrito judicial del Perú. Para el recojo de datos, se efectuó análisis documentario, a partir del cual se estudiaron las quejas, intervenciones oficiosas y sanciones disciplinarias; a la vez, se utilizó una escala valorativa, que midió el nivel de desarrollo de las habilidades gerenciales de los jueces.

Para el análisis de datos, se hizo uso de la estadística básica: Tablas de distribución de frecuencias, grafica de barras y lineales. Los resultados arrojaron que los jueces del distrito judicial de Áncash se encuentran en los niveles Básico y medio de desarrollo de habilidades gerenciales y que sus faltas disciplinarias se encuentran coadyuvadas por la necesidad de desarrollo de dichas habilidades; por lo que es posible afirmar que parte del perfil del juez que prevé el artículo 2 numeral 4 de la Ley de la Carrera Judicial N²9277, "conocimiento de la organización y manejo del despacho judicial", está conformado por habilidades gerenciales.

\section{ABSTRACT}

The study is based on the incidence of disciplinary processes of the judges and the need to develop managerial skills. The general objective was to propose the profile of a judge of the second level of the judicial career, based on managerial skills, to reduce disciplinary offenses.

In the framework of holistic research, it constitutes a projective study. The research design is descriptive-explanatory, transactional, field and propositive. The study population consisted of the all population, consisting of 43 judges of the second level of a judicial district of Peru. For data collection, documentary analysis was carried out, from which complaints, control interventions and disciplinary sanctions were studied; at the same time, a rating scale was used, which measured the level of development of the managerial skills of the judges.

For the data analysis, the basic statistics were used: Frequency distribution tables, bar graphs and linear. The results showed that, the judges of a one judicial district on Perú are in the Basic and middle levels of managerial skills development and that their disciplinary offenses are helped by the need to develop such skills; Therefore, it is possible to affirm that part of the profile of the judge provided for in article 2, numeral 4 of the Law on Judicial Careers No. 29277, "knowledge of the organization and management of the judicial office", is made up of managerial skills.

\section{PALABRAS CLAVE}

Juez del segundo nivel; faltas disciplinarias; habilidades gerenciales.

\section{KEYWORDS}

Second level judge; disciplinary offenses; management skills; emotional intelligence.

\section{INTRODUCCIÓN}

El estudio tuvo como punto de partida la incidencia de faltas disciplinarias de los jueces y la necesidad de desarrollo de habilidades gerenciales; las mismas que forman parte del elemento "conocimiento de la organización y manejo del despacho judicial" que forma parte del perfil del juez que prevé el artículo 2 numeral 4 de la Ley de la Carrera Judicial $\mathrm{N}^{\circ} 29277$.

Actualmente la ciudadanía califica la administración de justicia como lenta, ineficiente y corrupta, dicha percepción se construye desde la labor y actitud de los propios jueces. Casana (2015) resalta que, en la percepción y en el imaginario social, comúnmente el juez es percibido como un individuo todopoderoso que se inclina al poder político de turno o a los intereses económicos.

Efectivamente, en el desempeño de la función, los jueces incurren en faltas disciplinarias; según la Oficina de Control de la Magistratura (OCMA, 2015), a nivel nacional, se recibieron 32,219 quejas, tanto contra magistrados como contra servidores judiciales; de estas quejas, se impuso a los jueces, 416 amonestaciones, 259 multas, 55 propuestas de destitución y 44 suspensiones. En el caso del distrito judicial donde se realizó el estudio, según los registros de la Oficina Desconcentrada de Control de la Magistratura [ODECMA 2011-2018], a julio 
de 2018 se registraron 365 quejas, 191 procesos disciplinarios en trámite, se impusieron 102 amonestaciones, la mayor parte de ellas por retardo en el trámite de actuaciones judiciales. En los cinco últimos años de su existencia, el ex Concejo Nacional de la Magistratura, destituyó a cinco magistrados, atribuyéndoles la falta muy grave de no motivar sus decisiones, de los cuales 4 fueron jueces del segundo nivel de la carrera judicial.

Sobre la incidencia de faltas disciplinarias de los jueces, existen estudios dogmáticos y de análisis legislativo; no obstante, no se han encontrado estudios empíricos que busquen explicar las faltas disciplinarias, mucho menos, respecto de las causas o factores que lo condicionan. Dicho vacío motiva la presente investigación, partiendo del análisis de quejas, faltas disciplinarias y sanciones impuestas a los jueces, evidenciando que éstas se sustentan en retardo, falta de empatía, desconfianza sobre la integridad de los jueces y hasta en maltrato al justiciable, que compromete la necesidad de desarrollo de habilidades gerenciales complementado con el concepto de inteligencia emocional.

En tal sentido, el presente estudio busca responder al siguiente problema: ¿Cuál sería el perfil de un juez del segundo nivel, basado en habilidades gerenciales, para disminuir faltas disciplinarias en un distrito judicial del Perú?

El estudio tuvo como objetivo general, diseñar un perfil basado en habilidades gerenciales, para disminuir faltas disciplinarias de los jueces del segundo nivel de un distrito judicial del Perú, 2018. A su vez, se trazaron los siguientes objetivos específicos: a) Describir las quejas y actuaciones oficiosas que atribuyen faltas disciplinarias a los jueces del segundo nivel en un distrito judicial del Perú, 2018 , b) Determinar las faltas disciplinarias coadyuvadas por la necesidad de desarrollo de habilidades gerenciales, en las que incurren los jueces del segundo nivel de un distrito judicial del Perú, c) Identificar la necesidad de desarrollo de habilidades gerenciales de los jueces a partir de las faltas disciplinarias cometidas por los jueces del segundo nivel de un distrito judicial del Perú, 2018, y d) Proponer los componentes de un perfil basado en habilidades gerenciales, para disminuir faltas disciplinarias de los jueces del segundo nivel de un distrito judicial del Perú, 2018.
El estudio se justifica en una razón teórica, pues no existe una teoría estructurada que explique las razones por las cuales los jueces incurren en faltas disciplinarias, es un tema aún poco explorado y constituye una invitación a otros investigadores a profundizar en el presente estudio. Asimismo, se justifica en una razón metodológica, dado que, no se ha encontrado un instrumento válido y confiable que mida las habilidades gerenciales de los jueces; por lo que, se ha adaptado un instrumento de recolección de datos, valido y confiable que mide las habilidades gerenciales desde la percepción de los propios jueces; sin embargo, habiendo sido adaptado a partir de un instrumento elaborado para directivos, no propiamente para jueces, puede ser mejorado por futuros investigadores.

El estudio también se sostiene en una razón práctica, pues los resultados obtenidos, permiten efectuar un primer diagnóstico del nivel de desarrollo de habilidades gerenciales de los jueces del segundo nivel de la carrera, identificando el tipo de habilidades gerenciales que necesitan desarrollar para disminuir la incidencia de faltas disciplinarias en el distrito judicial donde se realizó el estudio, a partir del cual se propone un perfil que, no solo busca disminuir las faltas disciplinarias, sino a la vez puede constituirse en una herramienta valiosa para la gestión de despacho y fortalecimiento del liderazgo del juez, pudiendo ser replicado en todos los distritos judiciales del país.

Tiene relevancia social porque la idoneidad de los jueces es un asunto de interés nacional, y como quiera que, se parte del análisis de un aspecto patológico del desempeño judicial, las conclusiones a las que se arriba develan información valiosa respecto de la forma en la que dirigen y gestionan su despacho, que resultan de utilidad para planificar y gestionar su mejora.

El artículo comprende una breve descripción de los antecedentes de estudio, en el que se exponen tesis y artículos científicos sobre la variable de estudio; asimismo, las teorías en las cuales se sostiene el estudio; la descripción de los resultados que se trabajaron según la evaluación de cada uno de las unidades de información, jueces, estructurado de acuerdo a los objetivos del estudio, estos resultados hallados se contrastan con los antecedentes de estudio que sirvieron de base para la realización del presente estudio; las 
conclusiones estructuradas coherentemente con los objetivos del estudio y, finalmente, las recomendaciones.

\section{ANTECEDENTES}

Se exploraron antecedentes sobre la variable de estudio, no hallando investigaciones empíricas que se hayan ocupado del estudio de las faltas disciplinarias de los jueces del segundo nivel de la carrera judicial en el Perú, mucho menos respecto del diagnóstico de sus habilidades gerenciales como parte de la competencia "conocimiento de la institución y manejo del despacho judicial", previsto de manera general en el artículo 2 numeral 4 de la Ley de la Carrera Judicial como parte del perfil de un juez del segundo nivel. Sin embargo, existen estudios cualitativos relacionados a las citadas variables que apoyan la presente investigación.

Así, Díaz (2018) en su artículo científico "Aspectos susceptibles de cambios en la gerencia judicial desde la concepción del Juez", realizó un estudio en el ámbito judicial de Venezuela, que se apoyó en los lineamientos de la gerencia y la gestión del conocimiento, abordando desde la visión del juez, su actuación en una realidad que comprende condiciones organizacionales, administrativas e incluso de la vida social; lo que reclama que, entre otras capacidades como la jurídica, psicológica y ética, el juez, desarrolle habilidades gerenciales como parte de su perfil profesional.

A su vez, Cruchaga (2017) en su artículo científico "El ejercicio de la atribución disciplinaria por el Concejo General del Poder Judicial", estudia las faltas disciplinarias de los jueces en España, conductas que se evalúan en función de criterios de eficiencia y aspectos burocrático-administrativos, concluyendo que las faltas más comunes son por desatención y retrasos (54\%), seguida por faltas de respeto (16\%), abandono y ausencias (4\%), y parcialidad" (4\%), luego la ignorancia inexcusable en el cumplimiento de deberes funcionales identificado en sentencia firme, falta de atención a solicitudes de organismos superiores o de la organización judicial y finalmente, la falta de motivación.

Tamariz (2015) devela con entrevistas en profundidad, una mala percepción sobre los jueces del segundo nivel de un distrito judicial del Perú, por parte de los abogados, usuarios del sistema, comunicadores sociales y sindicato de trabajadores judiciales de dicho distrito judicial, respecto de la labor de los jueces, incidiendo especialmente en el maltrato y características de personalidad de los jueces, pero que no quejan por temor a represalias en el ejercicio profesional o en su proceso. La autora identifica que esta percepción se relaciona con la necesidad de desarrollo de habilidades gerenciales personales, especialmente de la habilidad de manejo de estrés.

Angelats (2015), en su tesis titulada "Análisis del Plan CERIAJUS en materia de formación ética de los magistrados y el servicio de justicia en nuestro país", hace propuestas puntuales con relación al perfil del juez peruano, proponiendo que, deben tener sólidos conocimientos, pero también base moral que asegure su independencia para rechazar intromisiones de todo tipo. La autora critica la selección y control de los jueces; afirma que, el reto es implementar una cultura de transparencia y ética en todo ejercicio de poder, para lo cual, debe enfatizarse la educación y la prevención; incide en resaltar que la calidad de buena persona no guarda relación con los grados y títulos académicos.

Dichas conclusiones complementan las conclusiones de Álvarez (2010), en su tesis titulada "El perfil de juez en la selección de jueces", quien plantea que el perfil del juez peruano no debe basarse solo en la ley, sino también, en los aportes que proporcionan las ciencias de la administración, específicamente, el enfoque de competencias laborales que se identifiquen en el ejercicio de la función; razón por la cual, propone agrupar las competencias en: éticas, cognitivas, personales y sociales y, competencias técnicas en las que, incluye las habilidades gerenciales.

\section{PLANTEAMIENTOS TEÓRICOS}

Respecto de los planteamientos teóricos, no se ha encontrado una teoría estructurada que explique las causas por las cuales los jueces incurren en falta disciplinarias; razón por la cual se han sistematizado conceptos que ayudan a explicar los resultados de la investigación; sin perder de vista que, como lo afirma Gómez (2015), la función social de los jueces ha evolucionado, a la par, con las profundas transformaciones que ha sufrido la sociedad; por lo que, dicha función siempre debe contextualizarse. En esa 
línea, actualmente, como afirman Hulpuş, \& Miricescu (2017), es posible que los métodos y técnicas exitosas del sector privado puedan ser aplicados al ámbito judicial, respetando las limitaciones y los requisitos que impone la ley a la organización judicial.

Sobre la delimitación conceptual de falta disciplinaria, Rodríguez (2016) lo define desde su significado etimológico, término que proviene del latín fallita, cuyo significado es la ausencia o carencia de algo; de allí que, falta disciplinaria vendría a ser la omisión o extralimitación en el deber encomendado, lo cual origina responsabilidad. Según Cartes (2015), la finalidad de la responsabilidad administrativa es cautelar que se cumplan los deberes funcionales encomendados. El Congreso Constituyente Democrático (1993), sobre la responsabilidad funcional de los jueces, establece en la Constitución Política del Perú, un principio de responsabilidad por su conducta funcional, como límite a la garantía de su independencia en el ejercicio de la labor jurisdiccional.

La gestión pública se ha ocupado muy poco respecto de la justicia, la "nueva gerencia pública" promueve la participación de los ciudadanos para definir lo que le conviene a la colectividad. Al respecto, Restrepo (2018) afirma que, se hace necesario un nuevo modelo administrativo gerencial en el Estado, sobre todo para la administración de justicia, que debe promover el acceso a los ciudadanos propiciando juicios transparentes y eficientes para incrementar la confianza en el sistema de justicia. En ese contexto, la investigación se inserta en las políticas del Acuerdo Nacional (Presidencia del Concejo de Ministros, 2002) Política de Estado 24, que guarda relación con un Estado eficiente, eficaz, moderno y transparente, por el cual el Estado debe mejorar su capacidad de gestión, siendo necesario implementar una profunda e integral reforma de la administración pública, revalorando y fortaleciendo la meritocracia en la carrera pública, con funcionarios $\mathrm{y}$ servidores altamente competitivos y con solvencia moral.

Asimismo, la investigación se inserta en la Política de Estado $\mathrm{N}^{\circ} 28$, orientada a institucionalizar el sistema de impartición de justicia; con cuyo objeto, entre otros, se acuerda la valorización y capacitación permanente de los jueces y se asume el compromiso de prever mecanismos de control para erradicar todo indicio de corrupción en el sistema de administración de justicia, para lo cual resulta indispensable la participación de la ciudadanía. Como afirma Ramos (2017), este tipo de políticas guarda estrecha relación con la calidad de la democracia, pues le da contenido a uno de sus elementos esenciales, que es el Estado de Derecho.

La independencia y la imparcialidad son valores rectores que deben guiar la actuación de los jueces cuando resuelven un conflicto o declaran derecho, sin injerencias de ningún tipo; es en este ámbito donde surgen las faltas disciplinarias más graves. Helmke (2017), al igual que Velásquez (2017), basados en estudios sobre crisis judiciales en países latinoamericanos, coinciden en que las crisis judiciales están relacionadas sistemáticamente a la intromisión del poder político e intereses particulares. Al otro lado del mundo, en China, se gestiona la justicia desde la perspectiva de la ideología socialista, como lo afirma Wang (2018), bajo el objetivo de la judicatura para el servicio político, de tal modo que, la resolución de conflictos como el control social son iguales; la agencia, si bien controla la calidad y la eficiencia del juicio, ignora la función de gestión de casos y debilita la independencia de los jueces.

En los Estados Unidos de Norteamérica, Black \& Owens (2016), examinan si los jueces norteamericanos sacrifican su independencia por objetivos profesionales; develando que, durante los períodos de vacantes para ascender a la Corte Suprema, es más probable que los jueces contendientes voten de manera consistente con las preferencias del presidente, que se pronuncien a favor de los Estados Unidos y que voten de forma disidente; en tanto, los jueces no contendientes no evidencian dicho comportamiento. Todos estos factores influyen en el desempeño judicial $\mathrm{y}$, por ende, en las faltas disciplinarias en las que incurren, siendo indispensable el desarrollo de habilidades gerenciales para afrontar estas injerencias y fortalecer la independencia de los jueces.

Whetten y Cameron (2005) definen las habilidades gerenciales como los lineamientos con los que el gerente pone en marcha, estrategias, prácticas, herramientas y técnicas de administración, las que no son independientes de los atributos, estilo y personalidad del 
directivo para lograr resultados eficaces. Los autores antes citados resaltan que las habilidades gerenciales se complementan con el concepto de Inteligencia Emocional (IE) desarrollado por Goleman (1998), que comprende 5 factores: autoconocimiento, autorregulación, motivación, empatía y habilidades sociales. El citado autor afirma que, las regiones cerebrales relacionadas con la autoconciencia guardan estrecha relación con la ética y con la toma de decisiones; así como el autodominio determina el estado cerebral más adecuado para cumplir una labor o función; y que, que la eficiencia personal guarda relación con estados de ánimo que aportan puntos positivos y negativos.

El autoconocimiento se relaciona con la inteligencia emocional. En ese contexto, Goleman (2015) afirma que, por ejemplo, el buen humor contribuye a la creatividad, a resolver mejor los problemas, a ser más flexibles; pero, a la vez resulta negativo, porque reduce el sentido crítico, conlleva a tomar decisiones apresuradas, a no tomar atención a los detalles; en ese contexto, hasta la rabia resulta de utilidad, moviliza energías y ayuda a centrar la atención en los detalles para superar obstáculos; pero a la vez, el mal humor afecta no solo al entorno, sino también a la propia persona.

En esa línea de ideas, Gomes, Guimaraes \& De Souza (2016) buscan identificar cómo los jueces brasileños perciben su rol social y como enfrentan los cuestionamientos sobre su indicado rol, clasificándolos en perfiles que corresponde a una motivación individual y social específica; y es que, estos cuestionamientos resultan ser fuente de quejas e investigaciones que atribuyen faltas disciplinarias a los jueces, siendo importante la forma en la que la enfrentan; de allí que, Alkozei, Schwab, \& Killgore (2016), resaltan la importancia de la inteligencia emocional en la toma de decisiones, siendo un factor que influye especialmente, cuando se tiene que decidir en situaciones emocionalmente difíciles.

Sobre la inteligencia emocional, Joseph, Jin, Newman, \& O'Boyle (2015), sostienen que es determinante para un buen desempeño laboral; razón por la cual debe ser un factor a evaluar en la selección de personal; pues, independientemente a los conocimientos, la inteligencia emocional determina el éxito en el desempeño del trabajo. En el ámbito judicial, Elek (2019) analiza las percepciones de jueces norteamericanos sobre tipos de conocimiento, aptitudes, habilidades y otras características necesarias para el trabajo judicial, destacando que los jueces reconocen que la emoción y las aptitudes interpersonales son componentes indispensables para la excelencia judicial; por lo que, las relaciones personales pueden afectar el desempeño judicial, por ende, incidir en su responsabilidad disciplinaria.

El juez es un ser humano, como tal tiene emociones y en tanto los conozca y los domine se desempeñará mejor en todos los aspectos de su vida, incluso en el ámbito profesional. Glynn \& Sen (2015), analizando datos sobre la vida familiar de jueces norteamericanos, encuentran que, condicionados al número de hijos que tengan, los jueces con hijas, votan de manera más feminista sobre cuestiones de género que los jueces que solo tienen hijos, concluyendo que, las experiencias personales de los jueces influyen en la forma en que toman decisiones y demuestra que, la empatía puede ser un componente de la manera en que los jueces deciden los casos, posición con la que también concuerdan Geher, Betancourt \& Jewell (2017).

Samamé (2016) hace alusión a la llamada Virtue Jurisprudence, como línea de investigación en filosofía del derecho, que se ocupa de las virtudes judiciales relacionando la justicia con la empatía, tratando de responder al cuestionamiento que la empatía debilita la imparcialidad de los jueces, afirmando que un juez prudente no se desborda en sus emociones, ya que las sujeta a la razón, y que de otro lado, la propia imparcialidad involucra emociones, porque no se trata de una labor fría, sino que está llena de valoración a los principios de justicia y fines morales; de allí que, las habilidades gerenciales basadas en inteligencia emocional coadyuvan las faltas disciplinarias en las que incurren los jueces.

Según la OCMA (2009), en la resolución $\mathrm{N}^{\circ} 52-2009$ emitida en la investigación $\mathrm{N}^{\circ} 0042$ 2008-Lima, la responsabilidad disciplinaria se puede generar por causas suscitadas dentro del proceso como por razones generadas fuera de él. Será fuera del proceso, cuando se trate de faltas que se cometen fuera del ámbito de la labor de juzgar; tal por ejemplo, la falta muy grave de ejercer otros empleos o cargos 
públicos paralelos a la función jurisdiccional, salvo la docencia; faltas que son percibidas como reprochables sin mayor debate, salvo el respeto por la privacidad del juez y sus derechos fundamentales; dado que, como lo dice Li (2018), si bien los jueces aportan sus diversas experiencias y valores personalísimos en la toma de decisiones, con lo que se incrementa la confianza de los usuarios, su intimidad respecto de las actividades ajenas a la judicial, debe ser pasible de protección en la medida en que éstas no erosionen la confianza pública en el poder judicial.

Sobre las razones dentro del proceso, esto es, por qué decide el juez, hay debate, pues podría constituir una injerencia que debilite o melle la independencia del juez en un caso concreto. Al respecto en esta resolución en comento, la OCMA (2009) citando a Martínez (2004), proporciona los motivos por los que surge la falta disciplinaria, clasificándolo en: "Del cuándo, del cómo y del qué". Surgen del "cuándo del procedimiento", cuando se refiere al cumplimiento de los plazos del proceso y la rapidez en el trámite; aspecto que se encuentra coadyuvado con la necesidad de desarrollo de habilidades gerenciales de los jueces, para gestionar eficazmente su despacho. Moreno (2012) afirma que, ello consiste en multiplicar la urgencia por la importancia del problema, categorizando los asuntos que debe resolver el directivo en: muy urgentes, pero poco importantes; importantes, pero poco urgentes; urgentes e importantes; poca urgencia gran importancia y otros, ni urgentes ni importantes.

Respecto del derecho a que los jueces resuelvan teniendo en cuenta la prioridad y la urgencia que el caso exija, el Poder Judicial viene desarrollando políticas, acorde a las políticas nacionales destinadas a resolver con prontitud los casos cuya naturaleza lo exige, tales por ejemplo los asuntos previsionales, en los que demandan adultos mayores, o las medidas de protección a las víctimas de violencia, o asuntos tutelares penales en los que se juzgan a menores de 18 años, los casos con detenidos, etc.

Igualmente mediante Ley $\mathrm{N}^{\circ} 30125$ se establecieron medidas para el fortalecimiento del Poder Judicial; bajo dicho marco, el Poder Judicial asumió el compromiso de establecer metas para optimizar la gestión del servicio de justicia para fortalecer el Poder Judicial, previa aprobación de su Concejo Ejecutivo, el mismo que mediante Resolución Administrativa
N¹10-2015-CE-PJ aprobó dichas metas, comprometiéndose a incrementar en el $2.5 \%$ la cantidad de procesos judiciales resueltos, entre otras medidas; el Poder Judicial desde el año 2012, y propiamente desde el año 2013, que se fija como año base estadístico, aprueba estándares de producción, esto es de expedientes principales resueltos para todos los órganos jurisdiccionales.

Sobre las faltas que se suscitan por el "cómo del procedimiento" se dan por la forma cómo se desarrolla la actividad en el trámite judicial del proceso; se trata de dirigir un equipo de trabajo para lograr metas de producción, pero también calidad de decisiones; para ello el juez debe reunir no sólo una alta formación jurídica, sino también habilidades gerenciales, por lo que, la modernización del Estado exige jueces cada vez más capacitados no sólo en ciencias jurídicas. Araújo \& Pestana (2017), afirman que el capital humano es el que contribuye al éxito de las organizaciones sostenibles y de alto rendimiento, de allí que las organizaciones requieren adoptar soluciones innovadoras que valoricen y reconozcan a los trabajadores que invierten su tiempo para mantenerse al día con las áreas de conocimiento que son relevantes para la organización.

La investigación toma el modelo de habilidades gerenciales propuestas por Whetten y Cameron (2005) que comprende grandes grupos de habilidades gerenciales, entre ellas: personales, interpersonales y de grupo. Las habilidades gerenciales personales comprende el desarrollo del autoconocimiento, partiendo por la identificación de los valores y prioridades personales, la forma y estilo de aprendizaje, así como su flexibilidad frente al cambio; así mismo, habilidad para manejar el estrés, tales como habilidad para afrontar los factores que lo condicionan, especialmente con una administración eficaz del tiempo, y el desarrollo de elasticidad; y, finalmente habilidad para solucionar problemas de forma analítica y creativa, utilizando un enfoque racional, creativo, fomentando la innovación en los demás.

Sobre las habilidades gerenciales interpersonales, Whetten y Cameron (2005) afirman que se trata de la capacidad para entrenar, orientar y escuchar, desarrollando una comunicación efectiva; también comprende la capacidad de incrementar poder positivamente, influenciar en los demás, motivarlos, ser capaz de identificar 
un bajo rendimiento y propiciar un clima laboral favorable, en el que, los logro sean recompensados; y finalmente, habilidad para manejar conflictos, siendo capaz de identificar las fuentes, los intereses y los factores que la originan, así como de seleccionar las estrategias para resolverlos.

Finalmente, las habilidades gerenciales de grupo, en las que lo autores citados ubican la habilidad para facultar y para delegar con responsabilidad, para trabajar en equipo, desarrollarlo, formarlo y fomentar su liderazgo. Así mismo, en este grupo, ubican la habilidad para generar cambios positivos, fomentando la iniciativa creativa e incentivando el desarrollo de nuevas habilidades. De Kock, Lievens, \& Born (2018) afirman que, las inteligencias específicas en el dominio de la cognición social, que implica la comprensión compleja de rasgos y comportamientos, hacen que un juez sea preciso.

La OCMA (2012) aclara que el derecho disciplinario no puede analizar el "qué del proceso"; es decir si el sentido de la decisión judicial es correcta o incorrecta, mucho menos si es justa o injusta. Los jueces son independientes, pero, ello no implica arbitrariedad, tienen el deber de explicar sus decisiones en hechos $\mathrm{y}$ en derecho. Esta actividad de los jueces es criticada por Pásara (2010), quien afirma que, las resoluciones judiciales en el Perú son "inentendibles", innecesariamente extensas, recargadas inútilmente de citas, sin claridad en el razonamiento. $\mathrm{Al}$ respecto, no puede perderse de vista que, las resoluciones judiciales y su publicidad son una especie de rendición de cuentas del Poder Judicial; acorde a ello el Estado viene implementando desde el año 2017, normativa destinadas a lograr que las resoluciones jurisdiccionales sean accesibles y comprensibles, lo cual guarda relación con la transparencia (Decreto Legislativo 1342).

Al respecto Grimmelikhuijsen \& Klijn (2015) afirman que, la transparencia judicial fortalece la confianza en los jueces, la que es necesaria para la aceptación voluntaria de las decisiones judiciales, para lo cual el juez debe tener una trayectoria de vida intachable, en la que se haya desenvuelto con altos valores éticos, pues no debe perderse de vista que dada la trascendencia de la labor de juzgar, que involucra la realización de valores, siempre será debatible; por ello, como afirma Samamé
(2016), no puede calificarse como correcta una acción sin tener en cuenta las cualidades o virtudes del sujeto moral, por eso no es posible separar en la realidad, la decisión judicial, del juez que lo dicta.

Sobre el perfil del juez, Casana (2008) propone un perfil del juez con competencias generales que agrupa en: Competencias cardinales, en los que considera cualidades personales imprescindibles para la labor, como integridad, independencia, imparcialidad; así mismo incluye habilidades como tolerancia al estrés, flexibilidad al cambio; competencias técnicas constituidas por los conocimientos y habilidades de comunicación, negociación, planificación y control, entre otros; competencias interpersonales como el liderazgo y trabajo en equipo; y competencias analíticas en las que ubica capacidad de razonamiento verbal y matemático, siendo esta propuesta una consultoría que la autora hizo para el ex Concejo Nacional de la Magistratura, que lo implementó de forma parcial.

\section{MÉTODO}

Del tipo de estudio. De acuerdo a su finalidad, constituye una investigación básica o fundamental, la cual busca aportar al conocimiento con fines prácticos a posteriori. Así mismo se enmarca en un estudio no experimental, en el sentido que no pretende controlar ni manipular variable alguna.

Por otra parte, atendiendo las particularidades de los objetivos del estudio, y en el marco de la investigación holística, la presente investigación es proyectiva. Al respecto, Hurtado (2000) considera que este tipo de estudio consiste en elaborar una propuesta que responda a solucionar un problema real o necesidad práctica de una organización, o grupo social, desde un diagnóstico de las necesidades de cambio, identificación de procesos causales o generadores y propensiones futuras; de allí que, el estudio, tuvo como finalidad diseñar el perfil de un juez del segundo nivel, basado en habilidades gerenciales, cuyo nivel de desarrollo constituye un factor generador o coadyuvante de las faltas disciplinarias.

Del diseño de estudio. De acuerdo con Hurtado (2002), un diseño de investigación debe responder a los objetivos de estudio en particular, por lo cual requiere observar 
Profile of a judge of the second level of the judicial career based on managerial skills

determinados aspectos cuya modificación es necesaria, así como sus procesos generadores. Por lo tanto, el diseño para la presente investigación es: Descriptivo-explicativo transaccional de campo y propositivo. En este sentido, en un primer momento que es descriptivo, se describe las necesidades de cambio debidamente caracterizados; en el segundo momento explicativo transaccional, se busca identificar el proceso generador a partir de las necesidades de cambio; y en el tercer momento se diseña la propuesta de solución que dé respuesta al proceso generador (Hurtado 2000). Asimismo, los datos se recolectan a partir de fuentes vivas de un grupo o institución, en un momento determinado.

Su esquema es el siguiente:

\section{Organización------------Evento a modificar--- ----Proceso generador----Propuesta}

Dónde:

Organización: 43 jueces del segundo nivel del distrito judicial donde se realizó el estudio.

Evento a modificar: observación de las quejas, intervenciones oficiosas y resoluciones de sanción disciplinaria impuestas.
Proceso generador: Descripción de la necesidad de desarrollo de habilidades gerenciales de los jueces.

Propuesta: Diseño del perfil de un juez del segundo nivel.

\section{Operacionalización de variables}

Variable de estudio: faltas disciplinarias

Variable coadyuvada /asociada: habilidades gerenciales

Variables de caracterización: sexo, especialidad y condición laboral.

\section{Población, muestra y muestreo}

De acuerdo a Hernández, Fernández y Baptista (2008), se denomina población censal cuando una población de estudio es reducida y las unidades de información son accesibles. En el presente estudio, la población estuvo constituida por 43 jueces que laboraron en 17 provincias del distrito judicial donde se realizó el estudio, de los cuales 26 jueces son titulares, 2 provisionales y 15 supernumerarios; por lo que la población fue censal.

Tabla $N^{\circ} 1$ - Distribución de la población censal de jueces del segundo nivel del distrito judicial donde se realizó el estudio, 2018.

\begin{tabular}{cclcccc}
\hline Juez & Sexo & \multicolumn{1}{c}{ Condición laboral } & Especialidad & No Quejas & No Invest & $\begin{array}{c}\text { Fecha de } \\
\text { ingreso }\end{array}$ \\
\hline 1. & F & Titular & Penal & 19 & 18 & 1997 \\
\hline 2. & M & Supernumerario & Penal & 4 & 6 & 2009 \\
\hline 3. & M & Titular & Penal & 2 & 0 & 2018 \\
\hline 4. & M & Supernumerario & Penal & 4 & 2 & 2007 \\
\hline 5. & M & Titular & Penal & 15 & 1 & 2009 \\
\hline 6. & M & Titular & Penal & 6 & 3 & 2016 \\
\hline 7. & F & Supernumerario & Mixto & 16 & 8 & 1997 \\
\hline 8. & M & Provisional & Civil & 177 & 7 & 1997 \\
\hline 9. & M & Titular & Penal & 16 & 34 & 2001 \\
\hline 10. & M & Titular & Civil & 30 & 18 & 2005 \\
\hline 11. & M & Supernumerario & Mixto & 4 & 4 & 2014 \\
\hline
\end{tabular}




\begin{tabular}{|c|c|c|c|c|c|c|}
\hline 12. & M & Supernumerario & Penal & 4 & 5 & 2011 \\
\hline 13. & M & Titular & Penal & 1 & 0 & 2018 \\
\hline 14. & M & Titular & Penal & 3 & 0 & 2017 \\
\hline 15. & M & Titular & Civil & 12 & 1 & 2011 \\
\hline 16. & $\mathrm{~F}$ & Supernumerario & Civil & 20 & 18 & 2003 \\
\hline 17. & M & Titular & Penal & 2 & 0 & 2018 \\
\hline 18. & M & Titular & Laboral & 3 & 2 & 2017 \\
\hline 19. & M & Titular & Mixto & 9 & 7 & 2013 \\
\hline 20. & M & Supernumerario & Penal & 11 & 16 & 2001 \\
\hline 21. & M & Supernumerario & Mixto & 3 & 2 & 2013 \\
\hline 22. & $\mathrm{~F}$ & Supernumerario & Mixto & 22 & 10 & 1999 \\
\hline 23. & M & Titular & Mixto & 53 & 17 & 2004 \\
\hline 24. & M & Titular & Mixto & 40 & 17 & 1996 \\
\hline 25. & $\mathrm{~F}$ & Titular & Mixto & 46 & 21 & 2009 \\
\hline 26. & $\mathrm{~F}$ & Supernumerario & Mixto & 3 & 2 & 2015 \\
\hline 27. & M & Titular & Mixto & 3 & 6 & 2013 \\
\hline 28. & $\mathrm{~F}$ & Supernumerario & Penal & 8 & 14 & 2009 \\
\hline 29. & $\mathrm{~F}$ & Titular & Mixto & 12 & 10 & 2007 \\
\hline 30. & M & Titular & Mixto & 17 & 13 & 2001 \\
\hline 31. & M & Titular & Penal & 61 & 15 & 2005 \\
\hline 32. & M & Titular & Mixto & 14 & 4 & 2002 \\
\hline 33. & $\mathrm{~F}$ & Titular & Laboral & 55 & 5 & 2009 \\
\hline 34. & $\mathrm{~F}$ & Titular & Civil & 36 & 6 & 1997 \\
\hline 35. & $\mathrm{~F}$ & Titular & Civil & 75 & 2 & 2002 \\
\hline 36. & M & Titular & Familia & 21 & 4 & 1999 \\
\hline 37. & $\mathrm{~F}$ & Supernumerario & Familia & 27 & 0 & 2003 \\
\hline 38. & $\mathrm{~F}$ & Supernumerario & Familia & 47 & 13 & 2001 \\
\hline 39. & $\mathrm{~F}$ & Supernumerario & Penal & 55 & 44 & 1997 \\
\hline 40. & $\mathrm{~F}$ & Supernumerario & Penal & 44 & 28 & 2002 \\
\hline 41. & M & Titular & Penal & 12 & 8 & 1999 \\
\hline 42. & M & Titular & Penal & 61 & 2 & 1999 \\
\hline 43. & $\mathrm{M}$ & Provisional & Penal & 10 & 21 & 2011 \\
\hline
\end{tabular}

Fuente: Distrito judicial de Áncash. Sistema de Información de la OCMA (SISOCMA). Elaboración: propia 
Profile of a judge of the second level of the judicial career based on managerial skills

Criterios de inclusión: jueces del segundo nivel con ingreso no mayor a enero del 2018 y que se encuentren trabajando a la fecha de aplicación de escala valorativa.

\section{Técnicas e instrumentos de recolección de datos}

En coherencia con los objetivos planteados en el estudio, se utilizaron las siguientes técnicas e instrumentos, así como sus respectivas unidades de información.

\begin{tabular}{|l|l|l|}
\hline \multicolumn{1}{|c|}{ Técnica } & \multicolumn{1}{|c|}{ Instrumento } & \multicolumn{1}{c|}{$\begin{array}{c}\text { Unidad de } \\
\text { información }\end{array}$} \\
\hline Encuesta & $\begin{array}{l}\text { Escala } \\
\text { valorativa } \\
\text { "Habilidades } \\
\text { Gerenciales". }\end{array}$ & $\begin{array}{l}\text { Jueces del segundo } \\
\text { nivel del distrito } \\
\text { judicial de Áncash. }\end{array}$ \\
\hline $\begin{array}{l}\text { Análisis } \\
\text { documental- } \\
\text { análisis de } \\
\text { contenido }\end{array}$ & $\begin{array}{l}\text { Ficha de análisis } \\
\text { de contenido }\end{array}$ & $\begin{array}{l}\text { Quejas, } \\
\text { intervenciones } \\
\text { oficiosas y } \\
\text { resoluciones de } \\
\text { sanción. }\end{array}$ \\
\hline
\end{tabular}

\section{De la técnica de la encuesta}

El uso de esta técnica permitió describir el nivel de desarrollo de habilidades gerenciales de los jueces del segundo nivel del distrito judicial donde se realizó el estudio y con ello su necesidad de desarrollo en la gestión de su despacho, desde el análisis de sus faltas disciplinarias.

Acorde a los objetivos de la presente investigación, se utilizó una escala valorativa denominada "Habilidades Gerenciales", instrumento que fue adaptado por la investigadora a partir de la propuesta de Whetten y Cameron (2005), instrumento denominado "Evaluación Personal de Habilidades Directivas", basado en un modelo teórico conformado por diez habilidades gerenciales agrupadas en tres dimensiones: personales, interpersonales y de grupo. Este instrumento mide el nivel de desarrollo de habilidades gerenciales desde la percepción de los propios jueces evaluados.

Dicho instrumento es de administración individual, sin límite de tiempo. Tiene 85 ítems, distribuido en 10 subescalas. La escala de evaluación de cada ítem es del 1 al 6, siendo 1 en fuerte desacuerdo, 2 en desacuerdo, 3 en poco desacuerdo, 4 en poco acuerdo, 5 de acuerdo y 6 en fuerte acuerdo. La escala valorativa contiene instrucciones por escrito, en ella se solicita al juez encuestado responder a cada ítem con sinceridad; así mismo, se le garantiza que, la información recabada es confidencial y anónima, pues no se consigna el nombre del evaluado ni su resultado particular; respecto de éstos, se garantiza que solo serán usados con fines de investigación científica.

\section{De su validez.}

Desde la teoría clásica de los test, los ítems en un test, constituyen una muestra representativa de todos los ítems que se pueden emplear para medir el constructo de interés. En tal sentido la escala valorativa "Habilidades gerenciales" fue sometida a la validez de contenido mediante el juicio de expertos. Para tal propósito se recogieron evidencias de 5 expertos y/o jueces en el tema, haciendo uso de dos matrices de validación, donde se evaluaron los criterios de: redacción, esencialidad, comprensibilidad y coherencia (Indicador-ítem e ítem- opción respuesta) de cada uno de los ítems.

\section{De su confiabilidad.}

En el presente estudio, se aplicó el método de consistencia interna, basado en la técnica de alfa de Cronbach. Para tal propósito, mediante un muestreo no probabilístico por conveniencia, se tomó una muestra de estudio piloto, a quienes se les aplicó la escala valorativa: "Habilidades Gerenciales", obteniendo los siguientes resultados:

Análisis estadístico de fiabilidad de la escala valorativa: Habilidades Gerenciales

\begin{tabular}{|c|c|c|}
\hline \multicolumn{2}{|c|}{$\begin{array}{l}\text { Resumen del procesamiento de } \\
\text { los casos }\end{array}$} & $\begin{array}{l}\text { Estadístico de } \\
\text { fiabilidad total }\end{array}$ \\
\hline & Elementos & Alfa de Cronbach \\
\hline Casos (Ítems) & 19 & \multirow{3}{*}{,986 } \\
\hline Excluidos $^{\mathrm{a}}$ & 0 & \\
\hline $\mathrm{N}^{\mathrm{o}}$ de elementos & 85 & \\
\hline
\end{tabular}

a. Eliminación por lista basada en todas las variables del procedimiento

El coeficiente de Alfa de Cronbach es 0,986, lo que significa que la escala habilidades gerenciales tiene un alto grado de confiabilidad. 


\section{Análisis documental}

Fuente: Distrito judicial de Áncash. Sistema de Información de la OCMA. (SISOCMA) Elaboración: Propia

Para recabar información se diseñó una ficha de análisis de contenido de quejas, intervenciones oficiosas y resoluciones emitidas por la Oficina desconcentrada de Control de la Magistratura (ODECMA) del distrito judicial de Áncash, obtenidas a partir del Sistema de Información de la OCMA (SISOCMA). Información que se obtuvo por la Ley de Transparencia en la Administración Pública, así como de publicaciones impresas en el Diario Oficial El Peruano y sus respectivas páginas web.

\section{Métodos de análisis de datos}

Los datos fueron procesados y analizados con estadígrafos descriptivos de la estadística básica: tablas de distribución de frecuencias, grafica de barras y lineales, y medidas de tendencia central. Asimismo para el procesamiento, análisis y extracción del conocimiento se utilizó el programa estadístico SPSS versión 19 y Excel 2010.

\section{Aspectos éticos}

Se basaron en los principios que estipula el Código de Ética de Investigación de la Universidad "César Vallejo", tales como: El respeto, la beneficencia, la justicia y el rigor científico. A su vez en las prácticas éticas de anonimato, confidencialidad, beneficencia y originalidad.

\section{RESULTADOS}

Con relación al primer objetivo específico, que fue describir las quejas y actuaciones oficiosas que atribuyen faltas disciplinarias a los jueces del segundo nivel en el distrito judicial donde se realizó el estudio, se determinó que el $100 \%$ de jueces fueron quejados alguna vez. De las 365 faltas registradas, la falta que con mayor frecuencia se les atribuye, es el de retardo que equivale al $44 \%$; a su vez, un significativo $28 \%$ fue quejado por negligencia, $11 \%$ por incumplimiento de sus deberes y $17 \%$ por otros tipos de faltas, tales como, desacatar disposiciones administrativas internas, hallazgos en visita de control, entre otros; estos resultados se plasman en la siguiente figura:

\section{Figura $\mathrm{N}^{\circ} 1$ - Distribución porcentual de quejas interpuestas contra los jueces del segundo nivel en el distrito judicial donde se realizó el estudio, 2018.}

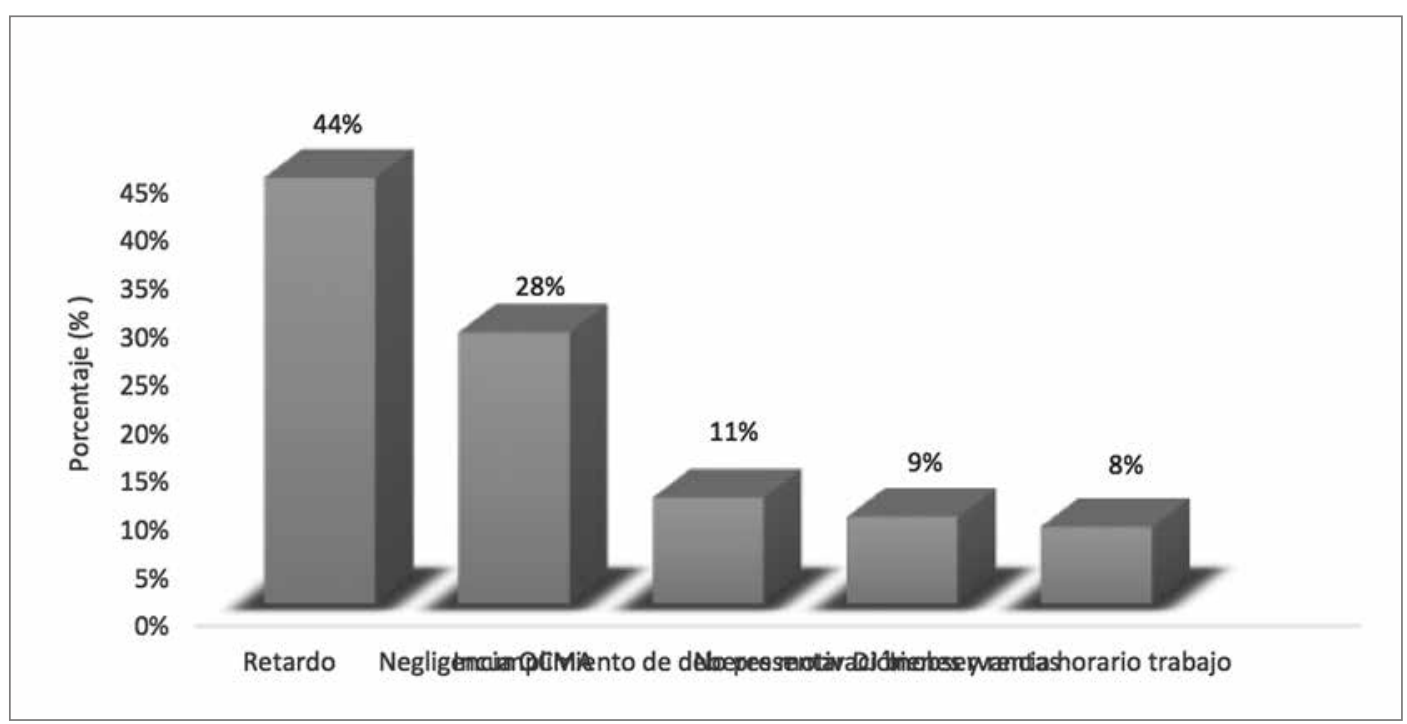

Fuente: Distrito judicial de Áncash. Sistema de Información de la OCMA (SISOCMA).

Elaboración: Propia 
Profile of a judge of the second level of the judicial career based on managerial skills

Asimismo, con relación a las faltas en las que incurrieron los jueces del segundo nivel de la carrera judicial y su gravedad, se determinó que la mayor cantidad de faltas acreditadas fueron por retardo injustificado, omisión o descuido en la tramitación de procesos $(43,8 \%)$, seguido por negligencia en el cumplimiento de sus deberes $(32,3 \%), 10,2 \%$ entre tardanzas y otras faltas leves. Asimismo, se determinó que un $9,8 \%$ de jueces incurrió en falta muy grave relacionada a vulnerar gravemente sus deberes; conforme se puede ver en la siguiente tabla.

Tabla $\mathbf{N}^{\circ} 2$ - Distribución de los tipos de faltas en las que incurrieron los jueces del segundo nivel del distrito judicial donde se realizó el estudio.

\begin{tabular}{lcc}
\hline \multicolumn{1}{c}{ Tipo de falta } & F & \% \\
\hline Muy grave 48.12 & 35 & 9,8 \\
Muy grave 48.13 & 4 & 1,1 \\
Grave 47 (0tros) & 9 & 2,5 \\
Leve 46.6 & 156 & 43,8 \\
Leve 46.10 & 115 & 32,3 \\
Leve 46.1 & 18 & 5,1 \\
Leve (Otros) & 18 & 5,1 \\
\hline Total & 356 & 100,0 \\
\hline
\end{tabular}

Fuente: Distrito judicial de Áncash. Sistema de Información de la OCMA. (SISOCMA)

Elaboración: Propia

Respecto de los procesos disciplinarios a los que dieron origen las quejas y actuaciones oficiosas del órgano de control, constituido por 365 que el $100 \%$, se discriminan los resultados con dos criterios: El trámite y el tipo de sanciones impuestas.

Con relación al trámite de las faltas disciplinarias, se determinó que algunas de las quejas interpuestas no prosperaron porque los jueces justificaron los hechos atribuidos inmediatamente; más de la mitad de los procesos disciplinarios se encuentran en trámite, y algunos de ellos han prescrito o caducado, conforme se grafica en la siguiente tabla.
Tabla $N^{\circ} 3$ - Distribución del estado de trámite de procesos disciplinarios de los jueces del segundo nivel del distrito judicial donde se realizó el estudio.

\begin{tabular}{lcc}
\hline \multicolumn{1}{c}{ Trámite procesos disc. } & F & \% \\
\hline Con justificación & 22 & $6,2 \%$ \\
Prescribió & 7 & $2,0 \%$ \\
Multas & 14 & $4 \%$ \\
Caducó & 5 & $1,4 \%$ \\
\hline Total & 48 & $13,6 \%$ \\
\hline
\end{tabular}

Fuente: Distrito judicial de Áncash. Sistema de Información de la OCMA. (SISOCMA)

Elaboración: Propia

Con relación a las sanciones que se impusieron a los jueces del segundo nivel de la carrera, del distrito judicial donde se realizó el estudio, se evidencia que, la mayor cantidad de sanciones fueron amonestaciones, seguida de suspensión y finalmente multas, como puede verse de la siguiente tabla.

Tabla $N^{\circ} 4$ - Distribución del tipo de sanciones de los jueces del segundo nivel del distrito judicial donde se realizó el estudio.

\begin{tabular}{lcc}
\hline \multicolumn{1}{c}{ Tipo de sanciones } & f & \% \\
\hline Amonestación & 102 & $28,7 \%$ \\
Multas & 14 & $4 \%$ \\
Suspensión & 15 & $4,3 \%$ \\
\hline Total & 131 & $37,0 \%$ \\
\hline
\end{tabular}

Fuente: Distrito judicial de Áncash. Sistema de Información de la OCMA (SISOCMA).

Elaboración: Propia

Es importante resaltar que, en los últimos 5 años de existencia del ex Concejo Nacional de la Magistratura, en parte del período estudiado, fueron destituidos 4 magistrados, quienes por no encontrarse laborando a la fecha de aplicación de la encuesta, no fueron incluidos en el estudio.

Respecto del segundo objetivo específico, que fue determinar las faltas disciplinarias y/o sanciones, coadyuvadas por la necesidad de desarrollo de las habilidades gerenciales, en las que incurren los jueces del segundo nivel del distrito judicial donde se realizó el estudio, se determinó que más de la mitad de las faltas 
disciplinarias en las que incurren los jueces del segundo nivel de la carrera está coadyuvada por la necesidad de desarrollo de habilidades gerenciales personales, lo que se describe en la siguiente tabla.

\section{Tabla $N^{\circ} 5$ - Distribución de la necesidad de desarrollo de habilidades gerenciales que coadyuvan las quejas y/o faltas disciplinarias}

\begin{tabular}{lcc}
\hline \multicolumn{1}{c}{$\begin{array}{c}\text { Tipo de habilidad } \\
\text { gerencial }\end{array}$} & f & \% \\
\hline $\begin{array}{l}\text { Habilidades gerenciales } \\
\text { personales }\end{array}$ & 179 & $52,3 \%$ \\
$\begin{array}{l}\text { Habilidades gerenciales } \\
\text { interpersonales }\end{array}$ & 75 & $21 \%$ \\
$\begin{array}{l}\text { Habilidades gerenciales de } \\
\text { grupo }\end{array}$ & 102 & $26,7 \%$ \\
\hline Total & 356 & $100,0 \%$ \\
\hline $\begin{array}{l}\text { Fuente: Distrito judicial de Áncash. Sistema de Información } \\
\text { de la OCMA (SISOCMA). } \\
\text { Elaboración: Propia }\end{array}$ & \\
\end{tabular}

Sobre el tercer objetivo específico, describir la necesidad de desarrollo de habilidades gerenciales de acuerdo a las faltas disciplinarias atribuidas y/o cometidas por los jueces del segundo nivel del distrito judicial donde se realizó el estudio, se determinó que más de las tres cuartas partes de jueces se encuentran en el nivel medio de desarrollo de habilidades gerenciales y menos de la cuarta parte en el nivel básico, reflejándose con ello su necesidad de desarrollo, prevaleciendo la necesidad de desarrollo de habilidades gerenciales personales, seguidas por las habilidades gerenciales de grupo y finalmente las habilidades gerenciales interpersonales, conforme se grafica en las siguientes dos figuras.

\section{Figura $\mathbf{N}^{\circ} 2$ - Niveles porcentuales de desarrollo de habilidades gerenciales de los jueces del} segundo nivel del distrito judicial donde se realizó el estudio, 2018.

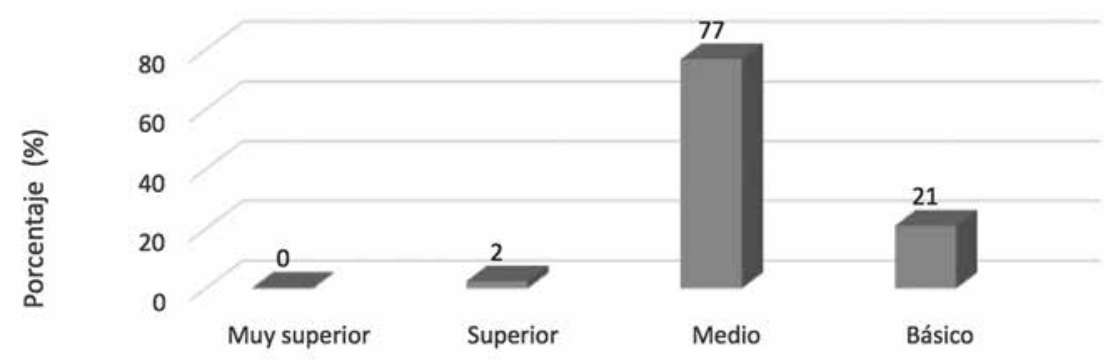

Fuente: Distrito judicial de Áncash. Sistema de Información de la OCMA (SISOCMA). 
Figura $\mathbf{N}^{\circ} 3$ - Incidencia porcentual de la necesidad de desarrollo, por tipo de habilidades gerenciales, de los jueces del segundo nivel del distrito judicial donde se realizó el estudio, 2018.

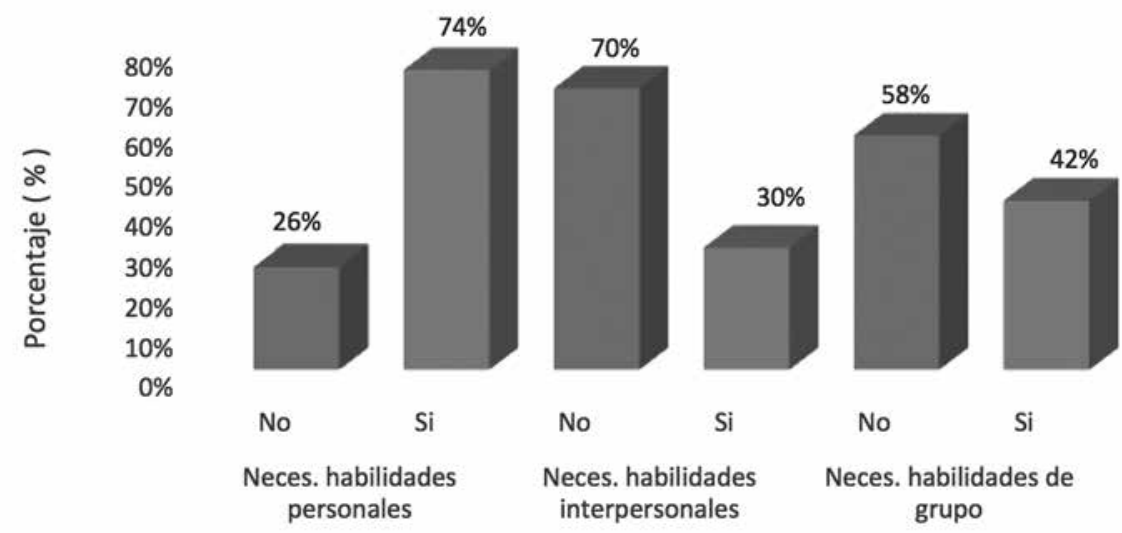

Fuente: Distrito judicial de Áncash. Sistema de Información de la OCMA (SISOCMA). Elaboración: Propia

De las variables de caracterización, se aprecia una marcada diferencia de necesidad de desarrollo de habilidades gerenciales de los jueces frente a las juezas; sin embargo, respecto de la condición laboral, se observa que no existen diferencias evidentes en la necesidad de desarrollo de habilidades gerenciales, entre jueces supernumerarios y titulares, conforme se puede ver de la siguiente tabla.

Tabla $\mathbf{N}^{\circ} 6$ - Tipo de habilidades gerenciales que necesitan desarrollar los jueces del segundo nivel del distrito judicial donde se realizó el estudio, según sexo y condición laboral.

\begin{tabular}{|c|c|c|c|c|c|c|}
\hline \multirow{2}{*}{\multicolumn{2}{|c|}{$\begin{array}{c}\text { Tipo de habilidades } \\
\text { gerenciales }\end{array}$}} & \multicolumn{2}{|c|}{ Sexo } & \multicolumn{3}{|c|}{ Condición laboral } \\
\hline & & \multirow{2}{*}{$\frac{\mathbf{F}}{13,3 \%}$} & \multirow{2}{*}{$\frac{\mathbf{M}}{32,1 \%}$} & \multirow{2}{*}{$\begin{array}{c}\text { Provisional } \\
0,0 \%\end{array}$} & \multirow{2}{*}{$\begin{array}{c}\text { Supernumerario } \\
26,7 \%\end{array}$} & \multirow{2}{*}{$\begin{array}{c}\text { Titular } \\
26,9 \%\end{array}$} \\
\hline Habilidades & No & & & & & \\
\hline personales & $\mathrm{Si}$ & $86,7 \%$ & $67,9 \%$ & $100,0 \%$ & $73,3 \%$ & $73,1 \%$ \\
\hline \multirow{2}{*}{$\begin{array}{l}\text { Habilidades } \\
\text { interpersonales }\end{array}$} & No & $66,7 \%$ & $71,4 \%$ & $50,0 \%$ & $73,3 \%$ & $69,2 \%$ \\
\hline & $\mathrm{Si}$ & $33,3 \%$ & $28,6 \%$ & $50,0 \%$ & $26,7 \%$ & $30,8 \%$ \\
\hline \multirow{2}{*}{$\begin{array}{l}\text { Habilidades de } \\
\text { grupo }\end{array}$} & No & $73,3 \%$ & $50,0 \%$ & $0,0 \%$ & $60,0 \%$ & $61,5 \%$ \\
\hline & $\mathrm{Si}$ & $26,7 \%$ & $50,0 \%$ & $100,0 \%$ & $40,0 \%$ & $38,5 \%$ \\
\hline \multicolumn{2}{|c|}{ Total } & $100 \%$ & $100,0 \%$ & $100 \%$ & $100,0 \%$ & $100 \%$ \\
\hline
\end{tabular}

Fuente: Distrito judicial de Áncash. Sistema de Información de la OCMA (SISOCMA).

Elaboración: Propia

Por especialidad, la mayoría de los jueces civiles muestran la necesidad de desarrollo de habilidades gerenciales personales e interpersonales; los jueces de familia en su totalidad muestran la necesidad de desarrollo de habilidades gerenciales personales; la mayoría de jueces mixtos, muestran la necesidad de desarrollo de habilidades gerenciales personales; $y$ los jueces penales en su mayoría muestran la necesidad de desarrollo de habilidades gerenciales personales y de grupo. 
Tabla 7. Tipo de habilidades gerenciales que necesitan desarrollar los jueces del segundo nivel del distrito judicial donde se realizó el estudio, según su especialidad

\begin{tabular}{lccccccccccc}
\hline \multicolumn{1}{c}{$\begin{array}{c}\text { Tipo de habilidades } \\
\text { gerenciales }\end{array}$} & \multicolumn{2}{c}{ Civil } & \multicolumn{2}{c}{ Familia } & Laboral & Mixto & \multicolumn{2}{c}{ Penal } \\
\hline Habilidades & $\mathrm{No}$ & $17 \%$ & 1 & $0 \%$ & 0 & $50 \%$ & 1 & $23 \%$ & 3 & $32 \%$ & 6 \\
personales & $\mathrm{Si}$ & $83 \%$ & 5 & $100 \%$ & 3 & $50 \%$ & 1 & $77 \%$ & 10 & $68 \%$ & 13 \\
& $\mathrm{~N}$ & $17 \%$ & 1 & $100 \%$ & 3 & $100 \%$ & 2 & $69 \%$ & 9 & $79 \%$ & 15 \\
Habilidades & $\mathrm{No}$ & & & & & & & \\
interpersonales & $\mathrm{Si}$ & $83 \%$ & 5 & $0 \%$ & 0 & $0 \%$ & 0 & $31 \%$ & 4 & $21 \%$ & 4 \\
Habilidades de & $\mathrm{No}$ & $67 \%$ & 4 & $100 \%$ & 3 & $50 \%$ & 1 & $77 \%$ & 10 & $37 \%$ & 7 \\
grupo & $\mathrm{Si}$ & $33 \%$ & 2 & $0,0 \%$ & 0 & $50 \%$ & 1 & $23 \%$ & 3 & $63 \%$ & 12 \\
\hline \multicolumn{1}{c}{ Total } & & & $\mathbf{6}$ & & 3 & & 2 & & 13 & & 19 \\
\hline
\end{tabular}

Fuente: Distrito judicial de Áncash. Sistema de Información de la OCMA (SISOCMA).

Elaboración: Propia

Finalmente, conforme al último objetivo específico, se propone los componentes el perfil de un juez basado en habilidades gerenciales, capaz de identificar las posibles barreras e implementar acciones concretas para garantizar el acceso a la justicia de la población en la que ejerce funciones; que resuelva con celeridad los procesos, motivando a su personal y trazando estrategias; que sea capaz de deponer sus disquisiciones personales al de la uniformización criterios para contribuir a la predictibilidad de las decisiones judiciales, sin que ello signifique claudicar a su independencia, con lo cual habrá más confianza en la impartición de justicia, contribuyendo a la gestión institucional con buenas prácticas, así como teniendo una mejor respuesta para la gestión de riesgo de desastres que se implemente.

\section{DISCUSIÓN DE RESULTADOS}

Se coincide con Díaz (2018), dado que la presente investigación también se apoya en los lineamientos de la gerencia y el estudio se aborda desde la perspectiva del Juez, concluyendo que parte de su perfil profesional debe estar conformado por el desarrollo de habilidades gerenciales. En la presente investigación se plantea que, dichas habilidades no solo son herramientas para conocer la organización y cumplir sus funciones administrativas, sino sobre todo para cumplir con eficiencia su función jurisdiccional; así como para conducirse en su vida social y personal. Al respecto, como lo afirma Feoli (2015), en las últimas décadas la judicatura se ha transformado, los jueces hoy se involucran en los asuntos políticos, al asumir sus funciones de control sobre los otros poderes del Estado, a lo que se ha llamado activismo judicial.

Asimismo, los resultados de la presente investigación guardan similitudes con los resultados obtenidos por Cruchaga (2017), en España; dado que ambos estudios se centran en estudiar las faltas disciplinarias de los jueces, diferenciándose el presente estudio en que no sólo se describen las faltas disciplinarias, sino que se determina un factor coadyuvante, que es la necesidad de desarrollo de habilidades gerenciales. Cruchaga (2017) concluye que las faltas más comúnmente identificadas son de desatención y retrasos (54\%). Estos resultados son similares al distrito judicial donde se realizó el estudio, en la que un $44 \%$ de faltas disciplinarias son por retardo u omisión de actos funcionales.

Se coincide en parte con Angelats (2015), pues presenta conclusiones que concuerdan y alimentan los resultados del presente estudio, así, por ejemplo, la citada investigadora afirma que se ha descuidado la formación de los magistrados y la evaluación de su desempeño. Respecto de la formación del magistrado, esta comprende un conjunto de elementos 
como formación jurídica, experiencia laboral, capacidad de razonamiento, entre otras; el presente estudio solo ha evaluado un aspecto del perfil del juez, que son las habilidades gerenciales, capacitación que no se proporciona en su formación universitaria, ni es materia de evaluación concreta para el acceso a la magistratura, pese a que forma parte del perfil que la ley exige para ser juez. En ese sentido se devela que, la mayoría de los jueces estudiados presenta un nivel de desarrollo básico o medio de éstas habilidades, y además se devela que ésta necesidad de desarrollo coadyuva las faltas disciplinarias en las que incurren; coincidiendo con la apreciación de la autora citada que, no bastan buenas leyes sino buenos jueces, con preparación no sólo en materia jurídica; ya que sus falencias afectan una correcta administración de justicia.

Sin embargo no concordamos con su apreciación respecto al control interno, que califica como poco transparente, considerando que hay limitación para juzgarse entre colegas; conclusión con la que no se coincide, dado que, constituye una opinión que no reporta evidencias concretas y atribuye claramente una conducta parcializada a los jueces de control disciplinario, que no se condice con los resultados evidenciados en el número de sanciones impuestas por la Oficina de Control de la Magistratura y el ex Concejo Nacional de la Magistratura.

En este estudio se evidencian algunas deficiencias del control interno, como la demora de los procesos disciplinarios, así como el hecho que, en la mayoría de los distritos judiciales, los jueces en ejercicio de funciones jurisdiccionales, tienen en adición a sus funciones la labor contralora, cuentan con poco personal, no especializado en la materia, y cumplen recargadas labores. Así en el distrito judicial donde se realizó el estudio, del total de quejas e investigaciones de oficio, un 53,6\% se encuentran en trámite y algunas de ellas prescribieron o caducaron, situación que refleja una respuesta tardía a las quejas ciudadanas; a ello se suma una alta carga laboral que no permite centrar la atención en la prevención y control de casos de envergadura.

Respecto de Álvarez (2010), guarda coherencia con los resultados de la presente investigación, pues el autor identifica una desarticulación entre el perfil de juez que señalan la
Constitución y la Ley y, los parámetros que se utilizan para su selección actual. En el presente estudio se ha efectuado un diagnóstico de sólo un componente de dicho perfil, que es el conocimiento de la organización y manejo del despacho judicial, determinándose que los jueces del distrito judicial donde se realizó el estudio necesitan desarrollar habilidades gerenciales, en base al cual se propone un perfil para desarrollar dicho componente del perfil de un juez, que se interpreta como perfil gerencial. Siendo ello así, se coincide con sus conclusiones referidas a que, la evaluación para la selección de jueces actualmente se reduce a valorar sus conocimientos jurídicos $\mathrm{y}$ que deberían exigirse otras competencias.

\section{CONCLUSIONES}

\section{General}

Las faltas disciplinarias en la que incurren los jueces del segundo nivel del distrito judicial donde se realizó el estudio, se encuentran coadyuvadas por la necesidad de desarrollo de habilidades gerenciales; por lo que, parte del perfil ideal de un juez del segundo nivel, para disminuir la incidencia de faltas disciplinarias, debe estar conformado por el desarrollo de habilidades gerenciales personales, interpersonales y de grupo.

El nivel de desarrollo de las habilidades gerenciales del total de los jueces del segundo nivel del distrito judicial donde se realizó el estudio, son valorados en los niveles básico y medio.

\section{Especificas}

Todos los jueces fueron quejados alguna vez. Del total de quejas interpuestas, un 6\% fue archivado al justificarse o desmentirse los hechos atribuidos inmediatamente; más de la mitad de los procesos disciplinarios se encuentran en trámite, y 3,4\% prescribieron o caducaron. Las faltas que con mayor frecuencia se les atribuye son leves, por retardo en el trámite de procesos judiciales, seguido por negligencia en sus funciones, incumplimiento de deberes y desacato de disposiciones administrativas internas. Coherentemente con ello, la mayor cantidad faltas disciplinarias acreditadas, son por retardo injustificado, omisión o descuido en la tramitación de procesos $(43,8 \%)$, seguido por negligencia 
en el cumplimiento de sus deberes $(32,3 \%) \mathrm{y}$, tardanzas y otras $(10,2 \%)$; en tanto, un $9,8 \%$ de jueces incurrió en falta muy grave relacionada a vulnerar gravemente sus deberes. La mayor cantidad de sanciones fueron amonestaciones, seguida de suspensión y finalmente multas.

Más de las tres cuartas partes de jueces se encuentran en el nivel medio de desarrollo de habilidades gerenciales y menos de la cuarta parte en el nivel básico, reflejándose con ello su necesidad de desarrollo de habilidades gerenciales personales, seguidas por las habilidades gerenciales de grupo y finalmente las habilidades gerenciales interpersonales.

Más de la mitad de las faltas disciplinarias en las que incurren los jueces del segundo nivel de la carrera judicial del distrito judicial donde se realizó el estudio, está coadyuvada por la necesidad de desarrollo de habilidades gerenciales personales, alrededor de una cuarta parte por habilidades gerenciales de grupo y, una quinta parte, por habilidades gerenciales inter personales. Existe una marcada diferencia de necesidad de desarrollo de habilidades gerenciales de los jueces frente a las juezas; no existiendo diferencias evidentes entre jueces supernumerarios y titulares.

La mayoría de los jueces civiles del distrito judicial donde se realizó el estudio, necesitan desarrollar habilidades gerenciales personales e interpersonales. Los jueces de familia en su totalidad necesitan desarrollar habilidades gerenciales personales. La mayoría de jueces mixtos necesitan desarrollar sus habilidades gerenciales personales. Finalmente, los jueces penales en su mayoría necesitan desarrollar habilidades gerenciales personales y de grupo.

\section{PROPUESTA}

Finalmente, sobre el perfil de un juez basado en habilidades gerenciales para disminuir faltas disciplinarias, se presenta la siguiente propuesta:

Título: Perfil de un juez del segundo nivel, basado en habilidades gerenciales, para disminuir faltas disciplinarias en el distrito judicial donde se realizó el estudio, 2018.

Fundamentación: El artículo 146 de la Constitución Política del Estado establece que el Estado garantiza la independencia e inamovilidad de los jueces, mientras observen conducta e idoneidad propias de su función. La Ley de la Carrera Judicial Ley $\mathrm{N}^{\circ} 29277$, sobre la idoneidad del juez, en su artículo 2 establece un perfil que comprende, capacidades y cualidades personales, entre otros, en su numeral 4 exige conocimiento de la organización y manejo del despacho judicial, siendo esta capacidad la que se desarrolla, proponiendo el desarrollo de habilidades gerenciales con enfoque de inteligencia emocional, planteada por Whetten y Cameron (2005), que han sido agrupadas en tres dimensiones: habilidades gerenciales personales, interpersonales y de grupo; las que se identifican del análisis de sus faltas disciplinarias, que son eventos patológicos donde se refleja la necesidad de desarrollo de capacidades y cualidades personales.

El desarrollo metodológico del presente perfil toma como marco referencial las "Normas Para La Gestión del Proceso de Diseño de Puestos y Formulación del Manual de Perfiles de PuestosMPP" aprobado por DIRECTIVA N ${ }^{\circ} 001-2016-$ SERVIR/GDSRH-Guía Metodológica Para Elaborar Perfiles de Puestos en las Entidades Públicas (Servir, 2016).

Diagnóstico: De los resultados de la investigación se encontró que más de las tres cuartas partes de los jueces del segundo nivel del distrito judicial donde se realizó el estudio evidencia un nivel medio de desarrollo de habilidades gerenciales, y los restantes se ubican en el nivel básico. De allí que, más de la mitad de las faltas disciplinarias que se les atribuye, está coadyuvado por la necesidad de desarrollo de habilidades gerenciales personales; más de la cuarta parte está coadyuvado por la necesidad de desarrollo de habilidades gerenciales de grupo y menos de la cuarta parte está coadyuvado por la necesidad de desarrollo de habilidades gerenciales interpersonales de los jueces.

De estos resultados, se aprecia una marcada diferencia de necesidad de desarrollo de habilidades gerenciales de los jueces frente a las juezas; sin embargo, respecto de la condición laboral, se observa que no existen diferencias evidentes en la necesidad de desarrollo de habilidades gerenciales, entre jueces supernumerarios y titulares. Por especialidad, la mayoría de los jueces civiles muestran la necesidad de desarrollo de habilidades gerenciales personales e interpersonales; los 
Profile of a judge of the second level of the judicial career based on managerial skills

jueces de familia en su totalidad muestran la necesidad de desarrollo de habilidades gerenciales personales; la mayoría de jueces mixtos, muestran la necesidad de desarrollo de habilidades gerenciales personales; y los jueces penales en su mayoría muestran la necesidad de desarrollo de habilidades gerenciales personales y de grupo.

Objetivo: Disminuir las faltas disciplinarias en las que incurren los jueces del segundo nivel del distrito judicial donde se realizó el estudio, mediante el desarrollo de habilidades gerenciales para la gestión de su despacho, los que se plasman en el presente perfil

Marco estratégico: La presente propuesta se inserta en la visión que tiene el Poder
Judicial, de ser una institución con magistrados comprometidos con el proceso de cambio, transformación y modernidad; que inspiren confianza en la ciudadanía. Así mismo, se inserta en la misión que tiene el Poder judicial de administrar justicia conforme a la Constitución y a la ley, dado que para ello requiere contar con magistrados respetados, probos, capaces, éticos y justos.

\section{Planteamientos estratégicos}

La presente propuesta será presentada a la Presidencia de la Corte Superior donde se realizó el estudio, a la Junta Nacional de Justicia y, a la Autoridad Nacional de Integridad y Control del Poder Judicial para su implementación y análisis.

\section{PERFIL DE HABILIDADES GERENCIALES:}

El juez debe tener la capacidad de identificar las posibles barreras e implementar acciones concretas para garantizar el acceso a la justicia de la población en la que ejerce funciones; que resuelva con celeridad los procesos, motivando a su personal y trazando estrategias; que sea capaz de deponer sus disquisiciones personales al de la uniformización criterios para contribuir a la predictibilidad de las decisiones judiciales, sin que ello signifique claudicar a su independencia, con lo cual habrá más confianza en la impartición de justicia, contribuyendo a la gestión institucional con buenas prácticas, así como teniendo una mejor respuesta para la gestión de riesgo de desastres que se implemente.

\section{Identificación del perfil}

Nombre del puesto: Juez del segundo nivel o Juez especializado.

Puesto al que reporta: Administrativamente al presidente de la Corte Superior de Justicia donde se realizó el estudio

\section{Objetivo del puesto}

Dirige el proceso judicial.

Conduce audiencias.

Toma decisiones resolviendo conflictos con relevancia jurídica o dilucidando una incertidumbre jurídica.

Gestiona el despacho judicial.

III. Control por el incumplimiento de deberes

El control por el incumplimiento de deberes es interno actualmente, a cargo del Órgano de Control de la Magistratura y Órgano Desconcentrado de Control de la Magistratura. Sin embargo, mediante Ley $N^{\circ} 30943$ (Publicado en El Peruano 8 de mayo de 2019) se crea la Autoridad Nacional de Control del Poder Judicial, que reemplaza a la OCMA y ODECMAS por un control externo.

\section{Coordinación interna}

Con la presidencia de la Corte Superior de Justicia para asuntos de carácter administrativo, jurisdiccionalmente es independiente, aunque se encuentra vinculado a decisiones emitidas por órganos jerárquicamente superiores en el caso concreto, según MOF aprobada por Resolución Administrativa -2014-P-CSJAN/PJ

\section{Comunicación externa}

Con las entidades del sistema de justicia, autoridades locales, regionales y nacionales, con fines de colaboración o cumplimiento de funciones o competencias asignadas por ley; así como con los abogados y usuarios del servicio. 
Especificaciones del cargo:

Artículo 8 de la Ley 29277. Requisitos especiales para Juez Especializado o Mixto.

1. Ser mayor de treinta (30) años;

2. Haber sido Juez de Paz Letrado o Fiscal Adjunto Provincial o secretario o Relator de Sala al menos por cuatro (4) años, o haber ejercido la abogacía o desempeñado la docencia universitaria en materia jurídica por un período no menor de cinco (5) años. Para el caso del ejercicio de la abogacía y la docencia universitaria, los períodos en una y otra condición son acumulables para alcanzar el mayor, en tanto no se hayan prestado en forma simultánea.

3. Haber superado la evaluación prevista para el porcentaje de acceso abierto;

4. Ser propuesto por la Comisión de Evaluación del Desempeño y haber aprobado los cursos especiales de ascenso que requiera la Academia de la Magistratura, para el porcentaje de acceso cerrado; y

5. Participar del programa de habilitación para los postulantes que ingresen a la carrera por este nivel.

\section{Perfil de habilidades gerenciales}

Juez del segundo nivel del distrito judicial donde se realizó el estudio

Fuente legal: Artículo 2 de la Ley N229277: (...) las principales características de un juez son: (...)

4. Conocimiento de la organización y manejo del despacho judicial.

\begin{tabular}{|c|c|c|c|}
\hline \multirow[t]{3}{*}{$\begin{array}{l}\text { Habilidades } \\
\text { gerenciales } \\
\text { personales }\end{array}$} & \multirow[t]{2}{*}{$\begin{array}{l}\text { Desarrollo del } \\
\text { autoconocimiento: Es } \\
\text { capaz de determinar } \\
\text { valores y prioridades, } \\
\text { identificar estilo } \\
\text { cognitivo, y evaluar } \\
\text { actitudes hacia el } \\
\text { cambio }\end{array}$} & $\begin{array}{l}\text { Revelación interna } \\
\text { y apertura (Esta } \\
\text { habilidad contribuye a la } \\
\text { independencia del juez, } \\
\text { frente a manipulaciones o } \\
\text { condicionamientos de todo } \\
\text { tipo.) }\end{array}$ & $\begin{array}{l}\text { Capaz de revelarse con autenticidad y } \\
\text { mostrarse como es frente a los demás. } \\
\text { Capaz de identificar sus fortalezas y } \\
\text { debilidades, su estilo de aprendizaje } \\
\text { (acopio y evaluación de información), } \\
\text { sus actitudes hacia el cambio, tolerancia } \\
\text { a la ambigüedad; de ese modo ese ser } \\
\text { humano será capaz de entenderse y } \\
\text { desenvolverse profesionalmente. }\end{array}$ \\
\hline & & $\begin{array}{l}\text { Conciencia del yo } \\
\text { (Habilidad que contribuye } \\
\text { a la toma de decisiones } \\
\text { justas y éticas) }\end{array}$ & $\begin{array}{l}\text { El carácter del juez debe haberse } \\
\text { forjado con la práctica de los valores de } \\
\text { justicia, equidad, cortesía, integridad, } \\
\text { transparencia, prudencia, diligencia, } \\
\text { honestidad, reserva y secreto profesional } \\
\text { (Código Iberoamericano de Ética } \\
\text { Judicial 2006). Debe tener un sentido } \\
\text { claro y delimitado de sus propios valores } \\
\text { y haber alcanzado un nivel de principios } \\
\text { de madurez moral. } \\
\text { Capaz de comprender las diferencias } \\
\text { de las personas, de valores, estilos, } \\
\text { actitudes; comprender la diversidad y } \\
\text { desarrollar empatía. }\end{array}$ \\
\hline & $\begin{array}{l}\text { Manejo del estrés } \\
\text { personal. } \\
\text { Es capaz de enfrentar } \\
\text { los factores estresantes, } \\
\text { administrar el tiempo } \\
\text { y desarrollar la } \\
\text { elasticidad. }\end{array}$ & $\begin{array}{l}\text { Eliminar el estrés } \\
\text { (Habilidad que contribuye } \\
\text { a la buena salud física y } \\
\text { mental del juez) }\end{array}$ & $\begin{array}{l}\text { Capaz de administrar su tiempo, saber } \\
\text { decir no. } \\
\text { Capaz de fomentar buenas relaciones y } \\
\text { cordialidad, sentido de pertenencia de } \\
\text { colaboración, trato amable y honesto. } \\
\text { Capaz de desarrollar inteligencia } \\
\text { emocional: reconocer y entender sus } \\
\text { propias emociones, controlarlas, auto } \\
\text { motivarse, ser empático, e interactuar } \\
\text { con los demás. }\end{array}$ \\
\hline
\end{tabular}




\begin{tabular}{|c|c|c|c|}
\hline & & $\begin{array}{l}\text { Desarrollar elasticidad } \\
\text { (habilidad para superar } \\
\text { los efectos negativos del } \\
\text { estrés) }\end{array}$ & $\begin{array}{l}\text { Capaz de tener un balance en la vida } \\
\text { desarrollando, además de actividades } \\
\text { propias del trabajo, actividad intelectual } \\
\text { diversa, física, espiritual, familiar, } \\
\text { cultural y social. } \\
\text { Capaz de cuidar su salud física y mental, } \\
\text { llevar una alimentación sana, practicar } \\
\text { alguna técnica de relajación, tener } \\
\text { fortaleza, compromiso, actitud de reto } \\
\text { frente al cambio. Fomentar trabajo en } \\
\text { equipo. Mantener relaciones familiares } \\
\text { sanas y sólidas. } \\
\text { Capaz de cuidar y desarrollar su } \\
\text { capacidad de concentración. }\end{array}$ \\
\hline & & $\begin{array}{l}\text { Manejo del estrés a corto } \\
\text { plazo }\end{array}$ & $\begin{array}{l}\text { Capaz de manejar técnicas de relajación } \\
\text { muscular, respiración, entre otros. }\end{array}$ \\
\hline & $\begin{array}{l}\text { Solución analítica y } \\
\text { creativa de problemas. }\end{array}$ & & $\begin{array}{l}\text { Capaz de definir el problema. } \\
\text { Capaz de acopiar datos objetivos } \\
\text { separándolos de las percepciones y las } \\
\text { suposiciones. } \\
\text { Capaz de desarrollar un pensamiento } \\
\text { flexible. } \\
\text { Saber escuchar } \\
\text { Contar con información suficiente } \\
\text { Ser creativo e innovador frente a casos } \\
\text { difíciles. }\end{array}$ \\
\hline $\begin{array}{l}\text { Habilidades } \\
\text { gerenciales inter } \\
\text { personales }\end{array}$ & $\begin{array}{l}\text { Coaching consultoría y, } \\
\text { comunicación de apoyo: } \\
\text { Es capaz de entrenar, } \\
\text { orientar y escuchar. }\end{array}$ & $\begin{array}{l}\text { Habilidad comunicación } \\
\text { de apoyo (Para mantener } \\
\text { buenas relaciones } \\
\text { laborales y producción) }\end{array}$ & $\begin{array}{l}\text { Ser congruente, que sus palabras } \\
\text { coincidan con sus pensamientos y } \\
\text { sentimientos. } \\
\text { Capaz de describir objetivamente un } \\
\text { suceso, su reacción y sugerir una forma } \\
\text { alternativa de actuar. } \\
\text { Capaz de abordar los problemas sin } \\
\text { atacar a las personas. } \\
\text { Capaz de validar a las personas con } \\
\text { respeto, flexibilidad. } \\
\text { Capaz de enfocarse en comportamientos } \\
\text { específicos, evitando generalizaciones, } \\
\text { extremas o excluyentes. } \\
\text { Ser capaz de escuchar de forma } \\
\text { comprensiva }\end{array}$ \\
\hline & & $\begin{array}{l}\text { Capacitación y orientación } \\
\text { (Para elevar la calidad del } \\
\text { trabajo) }\end{array}$ & $\begin{array}{l}\text { Capaz de aconsejar cómo realizar mejor } \\
\text { su trabajo y proporcionar información } \\
\text { para mejorar las habilidades laborales } \\
\text { del equipo. }\end{array}$ \\
\hline & & $\begin{array}{l}\text { Retroalimentación } \\
\text { negativa eficaz (Para } \\
\text { mantener un buen clima } \\
\text { laboral) }\end{array}$ & $\begin{array}{l}\text { Capaz de reconocer un buen desempeño } \\
\text { y corregir las conductas o actitudes } \\
\text { negativas o cuando surgen choque de } \\
\text { personalidades en el equipo. }\end{array}$ \\
\hline
\end{tabular}




\begin{tabular}{|c|c|c|c|}
\hline & \multirow[t]{2}{*}{$\begin{array}{l}\text { Ganar poder a } \\
\text { influencia.Es capaz de } \\
\text { ganar poder, ejercer } \\
\text { influencia e incrementar } \\
\text { autoridad. }\end{array}$} & $\begin{array}{l}\text { Ganar poder (Para } \\
\text { vencer las limitaciones } \\
\text { institucionales) }\end{array}$ & $\begin{array}{l}\text { Capaz de desarrollar poder institucional, } \\
\text { movilizar recursos para lograr los } \\
\text { objetivos de la organización. } \\
\text { Capaz de moldear su entorno. } \\
\text { Capaz de desarrollar poder personal } \\
\text { proveniente de sus atributos personales, } \\
\text { del conocimiento, especialización y } \\
\text { práctica de valores institucionales. } \\
\text { Ser confiable. }\end{array}$ \\
\hline & & $\begin{array}{l}\text { Ejercer influencia (para } \\
\text { inspirar) }\end{array}$ & $\begin{array}{l}\text { Capaz de persuadir, de lograr el apoyo y } \\
\text { compromiso de los demás para el logro } \\
\text { de objetivos institucionales, sin amenaza } \\
\text { ni intimidación. }\end{array}$ \\
\hline & $\begin{array}{l}\text { Motivación a los demás. } \\
\text { Es capaz de diagnosticar } \\
\text { bajo desempeño, crear } \\
\text { entorno motivador y } \\
\text { recompensar logros. }\end{array}$ & $\begin{array}{l}\text { Para lograr alto } \\
\text { rendimiento y satisfacción } \\
\text { laboral }\end{array}$ & $\begin{array}{l}\text { Capaz de diagnosticar } \\
\text { Capaz de establecer metas claras y } \\
\text { aceptadas } \\
\text { Capaz de crear un ambiente de trabajo } \\
\text { de apoyo mutuo. } \\
\text { Capaz de manejar técnicas de } \\
\text { recompensas justa, equitativa y } \\
\text { oportuna; así como de disciplina para } \\
\text { aprender. } \\
\text { Capaz de rediseñar el trabajo, asignando } \\
\text { labores, acorde a las habilidades e } \\
\text { intereses de los trabajadores. } \\
\text { Capaz de fomentar autonomía, pero con } \\
\text { retroalimentación. }\end{array}$ \\
\hline & $\begin{array}{l}\text { Manejo de conflictos. } \\
\text { Es capaz de identificar } \\
\text { las fuentes, seleccionar }\end{array}$ & Sobre iniciar & $\begin{array}{l}\text { Capaz de diagnosticar conflictos } \\
\text { interpersonales, qué lo alimenta y cómo } \\
\text { comenzó. }\end{array}$ \\
\hline & $\begin{array}{l}\text { las estrategias y resolver } \\
\text { confrontaciones. }\end{array}$ & Sobre responder & $\begin{array}{l}\text { Capaz de manejar conflictos. } \\
\text { Capaz de trazar estrategias en base al } \\
\text { diagnostico }\end{array}$ \\
\hline & & Sobre mediar & $\begin{array}{l}\text { Saber escuchar, facilitador del diálogo y } \\
\text { solución. }\end{array}$ \\
\hline $\begin{array}{l}\text { Habilidades } \\
\text { gerenciales de } \\
\text { grupo }\end{array}$ & $\begin{array}{l}\text { Facultamiento y } \\
\text { delegación. Es capaz } \\
\text { de facultar a los demás, } \\
\text { delegar y compartir } \\
\text { poder. }\end{array}$ & $\begin{array}{l}\text { Sobre facultamiento (Para } \\
\text { lograr colaboradores } \\
\text { más productivos, más } \\
\text { satisfechos y más } \\
\text { innovadores) }\end{array}$ & $\begin{array}{l}\text { Capaz de delegar responsabilidades } \\
\text { proporcionando recursos e información. } \\
\text { Capaz de generar confianza en su } \\
\text { capacidad y honestidad. }\end{array}$ \\
\hline & & Sobre delegación & $\begin{array}{l}\text { Capaz de identificar labores delegables } \\
\text { de aquellas que requieren su atención } \\
\text { personal. } \\
\text { Capaz de decir cuando, a quien y como } \\
\text { delegar }\end{array}$ \\
\hline
\end{tabular}




\begin{tabular}{|c|c|c|}
\hline \multirow{3}{*}{$\begin{array}{l}\text { Formación de equipos } \\
\text { efectivos y trabajo en } \\
\text { equipo. } \\
\text { Es capaz de diagnosticar } \\
\text { el desarrollo del equipo, } \\
\text { formar el trabajo en } \\
\text { equipo y fomentar el } \\
\text { liderazgo eficaz de } \\
\text { equipo. }\end{array}$} & Equipos líderes & $\begin{array}{l}\text { Capaz de desarrollar credibilidad en base } \\
\text { a su integridad personal, claridad en las } \\
\text { metas, optimismo. } \\
\text { Capaz de establecer una visión } \\
\text { inspiradora. }\end{array}$ \\
\hline & Afiliación a un equipo & $\begin{array}{l}\text { Ser capaz de asumir roles de facilitador } \\
\text { de actividades, construir relaciones, y } \\
\text { dar retroalimentación. }\end{array}$ \\
\hline & Trabajo en equipo & $\begin{array}{l}\text { Capacidad de diagnóstico. } \\
\text { Capacidad de formar un equipo, } \\
\text { cohesionarlo, manejar los } \\
\text { cuestionamientos y disconformidades, y } \\
\text { finalmente afrontar nuevos retos. }\end{array}$ \\
\hline $\begin{array}{l}\text { Liderar el cambio } \\
\text { positivo. }\end{array}$ & $\begin{array}{l}\text { Fomentar la desviación } \\
\text { positiva }\end{array}$ & $\begin{array}{l}\text { Capacidad para fomentar el cambio } \\
\text { hacia la excelencia, la perfección. }\end{array}$ \\
\hline $\begin{array}{l}\text { Es capaz de crear una } \\
\text { desviación positiva, } \\
\text { liderar un cambio } \\
\text { positivo, y movilizar } \\
\text { las habilidades de los } \\
\text { demás. }\end{array}$ & $\begin{array}{l}\text { Liderar un cambio positivo } \\
\text { Movilizar a los demás }\end{array}$ & $\begin{array}{l}\text { Capaz de identificar personas positivas y } \\
\text { posicionarlas en puestos claves; así como } \\
\text { fomentar conductas empáticas entre los } \\
\text { miembros del equipo, la contención en } \\
\text { los errores, y la gratitud. } \\
\text { Capacidad para comparar el desempeño } \\
\text { con estándares altos } \\
\text { Capaz de exponer valores y principios, } \\
\text { una visión de futuro positivo. } \\
\text { Capaz de generar compromiso con la } \\
\text { visión y trabajar para lograrlo. } \\
\text { Capaz de hacer que el cambio sea } \\
\text { continuo, y trascienda en el personal para } \\
\text { incrementar sus propias habilidades. }\end{array}$ \\
\hline
\end{tabular}

\section{FUENTES DE INFORMACIÓN}

\section{Fuentes bibliográficas}

Hernández, R., Fernández, C., \& Baptista, P. (2008). Metodología de la Investigación. La Habana, Cuba: Félix Varela.

Hurtado, J. (2000). Metodología de la investigación holística. Caracas, Venezuela: Fundación Sypal.

Hurtado, J. (2002). El proyecto de investigación holística. Bogotá, Colombia: Magisterio.

Tamariz, E. (2015). Necesidades de Desarrollo de Habilidades Gerenciales, de los Jueces del Segundo Nivel del Distrito Judicial, 2015 (Tesis de maestría en Gestión Pública Universidad Cesar Vallejo Trujillo-Perú).
Whetten, D. \& Cameron, K. (2005). Developing Management Skills (Sexta Edicción). Pearson: Prentice Hall.

\section{Fuentes hemerográficas}

Goleman, D. (1998). What makes a leader? Harvard Business Review, 93-102.

\section{Fuentes electrónicas}

Alkozei, A., Schwab, Z. \& Killgore, W. (2016). The role of emotional intelligence during an emotionally difficult decision-making task. Journal of Nonverbal Behavior, 40(1), 39-54. Recuperado de https://link.springer. com/article/10.1007/s10919-015-0218-4. 
Angelats Agreda, T. (2015). Análisis del plan CERIAJUS en materia de formación ética de los magistrados y el servicio de justicia en nuestro país. (Tesis de maestría en Derecho con mención en Política Jurisdiccional Pontificia Universidad Católica del Perú). Recuperado de http://tesis.pucp.edu.pe/repositorio/ handle/20.500.12404/6963

Araújo, J., \& Pestana, G. (2017). A framework for social well-being and skills management at the workplace. International Journal of Information Management, 37(6), 718-725. Recuperado de https://www.sciencedirect. com/science/article/pii/S0268401217305 996.

Black, R., \& Owens, R. (2016). Courting the president: how circuit court judges alter their behavior for promotion to the Supreme Court. American Journal of Political Science, 60(1). Recuperado de https://dialnet. unirioja.es $/$ servlet $/$ articulo? codigo $=5317237$.

Cartes, C. (2015). La responsabilidad disciplinaria de los funcionarios públicos: un estudio introductorio. Revista de Derecho Público, (82). Recuperado de https:// revistaderechopublico.uchile.cl/index.php/ RDPU/article/view/37285

Casana, P. (2008) Consultoría Perfil de Competencias de Jueces y Fiscales. Tercer Informe. Lima: Proyecto Mejoramiento de los Servicios de Justicia del Banco Mundial.

Casana, P. (2015). El juez. Ius et Praxis, (043). Recuperado de http://revistas.ulima. edu.pe/index.php/Ius_et_Praxis/article/ viewFile/334/320.

Cruchaga, S. (2017). El ejercicio de la atribución disciplinaria por el Consejo General del Poder Judicial. TransJus Working Papers; 2/2017. Recuperado de http://diposit.ub.edu/ dspace/bitstream/2445/123318/1/2-2017.pdf

De Kock, F. , Lievens, F., \& Born, M. (2018). The profile of the 'Good Judge'in HRM: A systematic review and agenda for future research. Human Resource Management Review. Recuperado de https://ink.library. smu.edu.sg/cgi/viewcontent.cgi?article $=6917 \&$ context $=1 \mathrm{kcsb}$ research.
Díaz, Y. (2018). Aspectos susceptibles de cambios en la gerencia judicial desde la concepción del juez. Revista arbitrada del Centro De Investigación y Estudios Gerenciales (Barquisimeto - Venezuela). Número 32. Recuperado de http://www. grupocieg.org/archivos_revista/Ed.\%20 32(116-132)-D\%C3\%ADaz\% 20Ysolina\%20 Betzab\%C3\%A9_articulo_id374.pdf

Elek, Jennifer (2019). Judicial Perspectives on Emotion, Emotion Management, and Judicial Excellence in the USA. Judicial Perspectives on Emotion, Emotion Management, and Judicial Excellence in the USA (March 26, 2019). Oñati Socio-Legal Series, Forthcoming. Recuperado de https://papers.ssrn.com/sol3/ papers.cfm? abstract_id $=3360513$.

Feoli, M. (2015). El nuevo protagonismo de los jueces: una propuesta para el análisis del activismo judicial. Revista de derecho (Coquimbo), 22(2), 173198. Recuperado de https://scielo. conicyt.cl/scielo.php? pid=S 0718 7532015000200006\&script $=$ sci_arttext.

Geher, G., Betancourt, K., \& Jewell, O. (2017). The link between emotional intelligence and creativity. Imagination, Cognition and Personality, 37(1). Recuperado de https://journals.sagepub.com/doi/ pdf/10.1177/0276236617710029.

Goleman, D. (2015). El cerebro y la inteligencia emocional: nuevos descubrimientos. B DE BOOKS. Recuperado de https://books. google.com.pe/books?hl=es\&lr $=\& \mathrm{id}=\quad \mathrm{o} \mathrm{kV}$ CgAAQBAJ\&oi $=$ fnd \&pg $=$ PT $9 \& d q=$ gole $\mathrm{man}++$ inteligencia + emocional\&ots $=\mathrm{Ocf}$ 1QBgW4c\&sig=eIUoua3B0sILrv9DXhN $\mathrm{Uz}$ o6R $4 \mathrm{U} \# \mathrm{v}=$ onepage $\& \mathrm{q}=$ goleman $\% 20 \% 20$ inteligencia $\% 20$ emocional $\& \mathrm{f}=$ false

Gomes, A., Guimaraes, T., \& de Souza, E. (2016). Judicial work and judges' motivation: the perceptions of Brazilian state judges. Law \& Policy, 38(2). Recuperado de https:// onlinelibrary.wiley.com/doi/abs/10.1111/ lapo. 12050. 
Profile of a judge of the second level of the judicial career based on managerial skills

Gómez, D (2015). El rol del juez en una sociedad democrática. Revista de Direitos e Garantias Fundamentais, 16(2). Recuperado de http:// sisbib.emnuvens.com .br/direitosegarantias/ article/download/728/264.

Glynn, A., \& Sen, M. (2015). Identifying judicial empathy: Does having daughters cause judges to rule for women's issues? American Journal of Political Science, 59(1). Recuperado de http://scholar.harvard.edu/files/aglynn/files/ daughters.pdf

Grimmelikhuijsen, S., \& Klijn, A. (2015). The effects of judicial transparency on public trust: evidence from a field experiment. Public Administration, 93(4), 995-1011. Recuperado de https://www.infona.pl/resource/bwmeta1. element.wiley-padm-v-93-i-4-padm 12149

Helmke, G. (2017). The Puzzle of Purges: Presidential Instability and Judicial Manipulation in Latin America. History. Recuperado de http://www.gretchenhelmke. com/uploads/7/0/3/2/70329843/helmke puzzleofpurges_2018.pdf.

Hulpuş, I., \& Miricescu, D. (2017). The Judicial Leader as an Agent of Change. Review of General Management, 25(1). Recuperado de http://www.managementgeneral.ro/ pdf/1 2017_9.pdf

Joseph, D., Jin, J., Newman, D. \& O’Boyle, E. (2015). Why does self-reported emotional intelligence predict job performance? A metaanalytic investigation of mixed EI. Journal of Applied Psychology, 100(2). Recuperado de https://www.researchgate.net/profile/ Daniel_Newman9/publication/287205621 Joseph Jin_Newman_O'Boyle 2015/ links/5673181e 08ae04d9b099c08c.pdf

Li, N. (2018). Peering into the Private Lives of Judges: Reconciling Judicial Accountability and Privacy. Dalhousie Journal of Interdisciplinary Management, 14. Recuperado de https://ojs.library.dal.ca/djim/ article/download/7872/7251

Martínez, M. (2004). La independencia Judicial. Centro de Estudios Políticos y Constitucionales, Madrid, 2004, P.350. Citado por OCMA en la Resolución $N^{\circ} 52$ de fecha 12 de junio de 2009 en la investigación $\mathrm{N}^{\circ} 0042$ 2008-Lima. Recuperado de http://ocma.pj.gob. pe/
Moreno, L. P. (2012). Libro de las habilidades directivas, El. 3 a edic. Ediciones Díazde Santos. Recuperado de http://www.editdiazdesantos. com/wwwdat/pdf/ 9788490520413.pdf.

Ocma http://ocma.pj.gob.pe/

Pásara, L. (2010). Responsabilidad de dar cuenta del desempeño de la función jurisdiccional (Tema Central). Recuperado de http://repositorionew.uasb.edu.ec/ bitstream/10644/2979/1/06-P\%C3\%A1sara. pdf

Ramos Rollón, M. (2017). La efectividad de las políticas de justicia de la última década en América Latina. Recuperado de http://old.clad. org/portal/publicaciones-del-clad/revista-cladreforma-democracia/articulos/068-junio-2017/ Ramos.pdf

Restrepo, J (2018). La gestión pública en la rama de la administración de justicia en Colombia, una mirada desde la teoría de la gestión y la teoría institucional. Ensayos: Revista de Estudiantes de Administración de Empresas, 10(1). Recuperado de https:// revistas.unal.edu.co/index.php/ensayos/ article/view/72496/66247

Rodríguez, F. (2016). Reflexiones sobre los criterios aplicados para determinar la gravedad o levedad de las faltas disciplinarias en el derecho disciplinario colombiano. Academia \& Derecho, (11), 227-258. Recuperado de. http://www.unilibrecucuta.edu.co/ojs/index .php/derecho/ article/viewFile/93/85

Samamé, L. (2016). Virtudes judiciales y empatía. Prometeica-Revista de Filosofía y Ciencias, (12), 63-79. Recuperado de https:// dialnet.unirioja.es/descarga/articulo/5331396. pdf

Velásquez, M. (2017). Judicial independence and bureaucratic judiciary. Perspectives from South America. TransJus Working Papers; 4/2017. Recuperado de http://diposit.ub.edu/ dspace/bitstream/2445/123320/1/4-2017.pdf

Wang, F. (2018). The history and future of civil judicial case management in China. Peking University Law Journal, 6(1), 237-271. Recuperado de https://www.tandfonline.com/ doi/full/10.1080/20517483.2018.1603642 


\section{Legislación}

Congreso Constituyente Democrático (1993). Constitución Política del Perú 1993.

Congreso de la República del Perú (13 de diciembre de 2013). Ley que establece medidas para el fortalecimiento del Poder Judicial. Ley $\mathrm{N}^{\circ} 30125$.

Congreso de la República del Perú. (4 de noviembre de 2008). Ley de la Carrera Judicial. Ley N²9277. Lima, Perú
Concejo Ejecutivo del Poder Judicial (11 de marzo de 2015). Resolución Administrativa $\mathrm{N}^{\circ} 110-2015-\mathrm{CE}-\mathrm{PJ}$. Recuperado de https:// www.pj.gob.pe/wps/wcm/ .../RA_110_2015_CE_ PJ+-+11_03_2015.pdf?

Presidencia del Concejo de Ministros (17 de octubre de 2002) Institucionalizan el Foro del Acuerdo Nacional D.S. 105-2002-PCM. 